REVIEW

\title{
Estrogen and Cerebrovascular Physiology and Pathophysiology
}

\author{
Dale A. Pelligrino* and Elena Galea \\ Neuroanesthesia Research Laboratory, University of Illinois at Chicago, Chicago, IL 60607, USA
}

Received September 8, 2000

\begin{abstract}
Numerous studies have uncovered a wide variety of estrogen effects with apparent cardiovascular benefits, the most recognized ones being vasodilation, anti-atherogenesis, diminished post-ischemic inflammation and anti-oxidant effects. This article provides an overview of the influence of estrogen on the cerebral vasculature, under physiologic and pathophysiologic conditions, and covers both acute and chronic effects. The discussion is primarily focused on the vasodilatory and anti-inflammatory actions of estrogen, since those particular estrogen influences have received the greatest attention in studies published to date. With respect to vasodilation, although some consideration is given to the role of other vasodilating mechanisms and factors, the emphasis is mostly placed on the endothelial isoform of nitric oxide synthase, eNOS, which has emerged as a clear target of estrogen. Some consideration is given to recent findings that suggest that estrogen can stimulate eNOS activity by decreasing the expression of the eNOS inhibitor caveolin-1. With regard to the ability of estrogen to counteract inflammation, potential mechanisms by which estrogen limits the post-ischemic leukocyte adhesion, and the expression of the inducible NOS, are discussed.
\end{abstract}

Keywords: Brain, Caveolin, Estrogen receptor, Inflammation, Leukocyte adhesion, Nitric oxide

1. Foreword ............................................... 137

2. Basic cellular mechanisms of estrogen action ................. 138

3. Estrogen and vasodilation ................................ 139 3.1. Acute effects

3.1.1. Non-cerebral tissues

3.1.2. Cerebral tissue

3.2. Chronic effects

3.2.1. Regulation of eNOS

3.2.1.1. Non-cerebral tissues

3.2.1.2. Cerebral tissue

3.2.1.3. Estrogen regulation of eNOS activity by indirect mechanisms

3.2.2. Regulation of endothelial prostanoid release

3.2.2.1. Non-cerebral tissues

3.2.2.2. Cerebral tissue

3.2.3. Regulation of endothelium-derived hyperpolarizing factor in peripheral and cerebral vascular tissue

\author{
3.2.4. Endothelium-independent regulation of \\ cerebral vasodilation \\ 3.2.4.1. Role of nNOS \\ 3.2.4.2. Role of the cholinergic system \\ 3.2.4.3. Role of synaptic remodeling \\ 3.2.4.4. Role of noradrenaline and adenosine
}

4. Estrogen and cerebrovascular inflammation.. 147

4.1. Inflammatory events in endothelial cells

4.2. Effect of estrogen on inflammation in noncerebral endothelium

4.3. Counter-inflammatory effects of estrogen: role of $\mathrm{NF} \kappa \mathrm{B}$

4.4. Effect of estrogen on inflammation in cerebral tissue

4.4.1. Effect on adhesion molecule expression

4.4.2. Effect on iNOS and other inflammatory proteins

5. Concluding remarks.

\section{Foreword}

It is well-established that the incidence of cardiovascular disease, including stroke, and related mortality are lower in

\footnotetext{
*Corresponding author. FAX: +1-815-333-1493
}

E-mail: dpell@uic.edu females prior to menopause, when compared to males and post-menopausal females. It is quite likely that the protection in pre-menopausal females relates to higher levels of circulating estrogens, principally $17 \beta$-estradiol $\left(\mathrm{E}_{2}\right)$. The identification of the specific mechanisms involved in $E_{2}$ related cardiovascular defense has been the objective of numerous experimental studies, as summarized in recent 
excellent reviews $(1,2)$. The results of such investigations have uncovered a wide variety of $E_{2}$ effects with apparent cardiovascular benefit, some of the best-known actions being vasodilation, anti-atherogenesis, diminished postischemic inflammation and anti-oxidant effects.

The major objective of the present paper will be to provide an overview of estrogen's influence on the cerebral vasculature. In comparison to the periphery, the brain has received very little attention in this regard. Nevertheless, the information gained from studies in non-cerebral vascular tissue does provide a template for discussing possible estrogen actions in brain vessels, and a reference point for comparison to the limited currently available data regarding estrogen and the cerebral circulation. However, cerebral vessels exist in an environment that is quite different from other vascular tissues. The presence of an extensive neuronal and glial influence has a profound effect on cerebrovascular function and reactivity to endogenous substances, including estrogen. In particular, astrocytes and astrocyte-derived factors not only may regulate cerebral hemodynamics, but also may play a major role in establishing the unique phenotype of cerebrovascular endothelial cells. This is exemplified by the presence of endothelial cell tight junctions, which form the blood-brain barrier and limits the entry of blood-borne substances into the brain; and by the apparent resistance of cerebral endothelium to inflammatory reactions (e.g., leukocyte adhesion and diapedesis). Moreover, general and segmental differences in vascular smooth muscle and endothelial cell receptor populations, ion channels and expression of proteins related to control of vessel function, compared to other vascular beds, also contribute to the "unique" character of the cerebral vasculature. Thus, one must be cautious when applying information gained from studies in non-cerebral tissues to any discussion of estrogen and vascular function in the brain.

With such caveats in mind, this review begins with a somewhat generic summary of basic cellular mechanisms of estrogen action. This is followed by a more specific discussion of estrogen's influence on vasodilating function, with a major emphasis on the endothelial isoform of nitric oxide synthase (eNOS). A consideration of estrogen's purported ability to act as a counter-inflammatory agent is provided, with some attention given to post-ischemic leukocyte adhesion and regulation of inducible NOS (iNOS) expression. In addition, some discussion of acute versus chronic effects is presented.

\section{Basic cellular mechanisms of estrogen action}

The "classical" mode of estrogen action is via a stereoselective activation of intracellular receptors. Thus, $17 \beta$ estradiol (but not $17 \alpha$-estradiol) binds to its receptor forming a complex that regulates nuclear transcriptional activity either directly, via interactions with palindromic sequences within gene promoters (i.e., estrogen response elements) or indirectly through other transcriptional modulators. There are two structurally distinct estrogen receptors, ER- $\alpha$ and ER- $\beta$. Based upon protein and/or mRNA analyses, these receptors appear to be expressed in a wide variety of tissues, including the brain and vascular cells $(2-4)$. Differences exist in the patterns of distribution of the two receptor types in the brain, vascular tissues and other structures, although co-expression of both receptors within the same cells has been noted. The basic receptor complex exists either as a homodimer (i.e., $\alpha / \alpha$ or $\beta / \beta$ ) or a heterodimer $(\alpha / \beta)$, with each form possessing unique transcriptional properties. There are some estrogen-related experimental findings that cannot be explained through the classical ERs, but appear to involve genomic effects nonetheless. This raises the possibility that a yet unidentified $\mathrm{ER}$ and/or estrogen-modulated pathway for the regulation of gene product expression may exist (5).

The preceding paragraph describes a genomic process of estrogen action that is likely to require hours of estrogen exposure for changes in protein expression to be realized. However, estrogen also can elicit acute physiologic effects. One of the earliest acute actions of estrogen to be identified was its ability to promote vasodilation (6). Acute responses to estrogen, like vascular relaxation, that occur within seconds to minutes of estrogen administration cannot be attributed to genomic mechanisms. Current evidence points to the possibility of a cell surface receptor that, in endothelial cells, may be linked to increased $\mathrm{Ca}^{2+}$ entry (7) and, in vascular smooth muscle cells, may be coupled to intracellular cAMP generation $(8,9)$, stimulation of $\mathrm{Ca}^{2+}$ dependent $\mathrm{K}^{+}$channels $(10,11)$ or blockade of voltagedependent $\mathrm{Ca}^{2+}$ channels (12). It is uncertain, at this time, as to whether that cell surface target of estrogen action indeed represents a novel receptor (see, for example, ref. 13) or is a "classical" ER localized to the plasma membrane $(7,14$, 15). Recent findings would appear to support the latter. That is, evidence indicated that the acute actions of estrogen are actually mediated through ER- $\alpha$ and/or ER- $\beta$, but via a different signal transduction route from that utilized to influence gene transcription. That conclusion is based upon findings that the acute reactions to estrogen can be blocked by pretreatment with classical ER pure antagonists, such as ICI 182,780, and that such responses do not occur when $17 \alpha$-estradiol is given (16). These findings may also be consistent with a process whereby a stereoselective plasma membrane estrogen binding protein (13) is linked to a classical ER in the cytoplasm. 


\section{Estrogen and vasodilation}

The discussion of the principal mechanisms involved in the vasodilating influence of estrogen has been organized according to acute versus chronic estrogen actions. Acute estrogen effects are a function of estrogen's ability to act as a direct vasodilating agent. Chronic estrogen actions relate to the steroid's capacity to facilitate vasodilation through either influencing the transcription of proteins that participate directly in vasodilation or via modulating the expression and/or activity of other proteins with indirect involvement in vasodilation.

\subsection{Acute effects}

\subsubsection{Non-cerebral tissues}

Based upon the results of multiple studies, it would appear that the acute vasodilating effects of estrogen can occur through both endothelium-dependent and -independent (i.e., direct vascular smooth muscle) mechanisms. With respect to endothelium-derived factors, two possibilities have been considered: increased generation of eNOSderived NO and enhanced synthesis of vasodilator prostanoids.

In cultured endothelial cells harvested from a variety of non-cerebral sources, many reports have indicated that acute estrogen treatments, at physiologically relevant concentrations, promote increased NO generation $(7,14,17-$ 19). Acute $E_{2}$-induced increases in blood flow in vivo or relaxation of vessels ex vivo have been reported to be NO-dependent in some $(20-22)$, although not all (2327), relevant studies. Rather than directly increasing endothelial $\mathrm{NO}$ production, acute $\mathrm{E}_{2}$ administration may also act to potentiate responses to the eNOS-dependent vasodilators like acetylcholine. This "permissive" action of $E_{2}$ has been demonstrated in the coronary circulation of postmenopausal human females (28).

Like the body of experimental information regarding NO-related mechanisms, the results of some studies support a role for vasodilator prostanoids in the acute actions of estrogen $(29,30)$, while others do not $(25,27,31)$. Of some additional interest, many of the studies on peripheral vascular tissue, reporting prostanoid- and/or NO-dependence, also found that the acute $\mathrm{E}_{2}$ response could be blocked by pretreatment with an estrogen receptor blocker $(7,14$, $17-19,22)$. This suggests that the acute activation of the pathways leading to increased NO and prostanoid generation are linked to classical ERs, although the mechanisms involved in that linkage are unknown.

Another potential site for acute estrogen actions is the vascular smooth muscle cell. Evidence for direct actions of estrogen on non-cerebral vascular smooth muscle has been obtained in isolated cell systems and in endotheliumdenuded vessel preparations. Some reports have revealed a stereoselective effect of estrogen $(9,27,32)$ on vascular smooth muscle that may $(9,32)$ or may not $(25,27,33)$ involve classical estrogen receptors. Other publications point to direct vascular smooth muscle relaxant effects of estrogen that variously depend upon: a) increases in intracellular cAMP $(9,26)$ or cGMP $(26)$; b) activation of the cGMP-dependent kinase (34); c) potentiation of $\mathrm{Ca}^{2+}$-dependent $(11,34)$ or ATP-sensitive $(25) \mathrm{K}^{+}$channel activity; or d) blocking voltage-dependent plasma membrane L-type $\mathrm{Ca}^{2+}$ channel function $(25,33,35)$.

\subsubsection{Cerebral tissue}

In the cerebral circulation, several studies have shown that acute estrogen administration is capable of eliciting vasodilations, but only at concentrations (micromolar) seemingly well beyond the physiologically relevant range $(36-40)$. To our knowledge, only one preliminary study, in newborn pigs, has directly addressed whether NO plays a role in the estrogen action. Thus, Zuckerman and Son (36) found that pial arteriolar diameter increases elicited by high-dose $\mathrm{E}_{2}$ were unaffected by NOS inhibition. In another study, Ghanam et al. (38) reported that acute $\mathrm{E}_{2}$ applications relaxed isolated segments of rabbit middle cerebral arteries via an endothelium-independent process that appeared to involve restriction of $\mathrm{Ca}^{2+}$ entry in vascular smooth muscle cells - a finding consistent with a lack of any eNOS influence. In the rabbit, topical application of $\mathrm{E}_{2}$ in $\mu \mathrm{M}$ amounts elicited a pial arteriolar dilation that was blocked in the presence of an ER antagonist (40). However, the role of NO in that vascular response was not addressed. In summary, unlike in the periphery, where there is some evidence to indicate that NO may play a role in the acute vasodilating effects of $E_{2}$, comparable evidence in the cerebral vasculature is lacking.

Whether, as in non-cerebral tissues, prostanoids may contribute to the acute vasodilatory actions of $E_{2}$ in brain has not been extensively explored. Indeed, only one preliminary report has addressed that issue. In that study, the vasodilating actions of high-dose $E_{2}$ on pial arterioles of neonates was found to be reduced in the presence of indomethacin (36), suggesting some role for prostanoids in that response.

One common feature in the studies cited above regarding the acute cerebrovascular effects of $E_{2}$, is that pharmacologic (i.e., micromolar) doses were required to elicit the effects observed. Thus, the physiologic relevance of these data might be called into question. However, the picomolar to nanomolar amounts of circulating $\mathrm{E}_{2}$ found in intact females refers to the free, unbound steroid content. As much as $98 \%$ of the total $\mathrm{E}_{2}$ content is protein-bound (41), with $50-60 \%$ of that fraction bound to albumin and the remainder to sex hormone-binding globulin (42). Since $E_{2}$ binds to albumin with low affinity (but high capacity), albumin- 
bound estrogen is often included in the bioavailable fraction (43). Therefore, the physiologically relevant vasoactive threshold concentration for $\mathrm{E}_{2}$ action may actually be $1-2$ orders of magnitude greater than indicated by the free steroid level. As a consequence, the results of studies employing isolated vessel or local application in vivo approaches should not be dismissed simply because the $E_{2}$ doses used to elicit a response exceeded the range of $E_{2}$ concentrations seen in the circulation of intact females. On the other hand, since $\mathrm{E}_{2}$-induced cerebral vasodilation appears to involve an ER (40), one must also consider physiologic relevance in terms of the $E_{2}$ concentrations capable of activating the ER mediating the vascular response. In vitro estimates of $\mathrm{E}_{2}$ binding to its receptor (in ER-transfected cells) indicate a high binding affinity, with the dissociation constant $\left(\mathrm{K}_{\mathrm{d}}\right)$ lying in the subnanomolar to nanomolar range (44). This would appear to be more in line with concentrations of unbound $\mathrm{E}_{2}$ measured in the circulation and favor nanomolar $\mathrm{E}_{2}$ as the physiologically relevant level, at least when considering ER-mediated actions. However, the results of a recent study could be interpreted to suggest that much higher estrogen concentrations may be needed to activate the ER in the cerebral circulation in vivo. Thus, although topically-applied $\mathrm{E}_{2}$ was found to elicit a dose-dependent pial arteriolar dilation, this only occurred in the seemingly supraphysiologic $0.1-100 \mu \mathrm{M}$ concentration range, and those responses were prevented in the presence of pharmacologic blockade of the ER (40). Obviously, further study is needed before any explanation can be attempted regarding this wide disparity in the apparent ER sensitivities to $\mathrm{E}_{2}$, when comparing cerebral vessels in vivo and ER-transfected cells in vitro.

In addition to direct actions on the vessels, a number of reports exist where the acute effects of $E_{2}$ on brain neuronal function or metabolic activity have been addressed. Because changes in neuronal activity are often linked to changes in cerebral vascular tone, such publications are of some relevance to the present discussion. In a paper published more than 15 years ago, it was shown that high-dose intravenous $E_{2}$ increased metabolic activity in multiple brain regions (45). The results of subsequent studies have indicated that acute $\mathrm{E}_{2}$ administration, either in vivo or in vitro, can antagonize the actions and/or reduce the receptor sensitivities of neurotransmitters or neuromodulators associated with repression of neuronal activity in a number of brain regions, by a mechanism that may involve interference with inhibitory G-protein function (46-50). Other studies have suggested that acute applications of $E_{2}$ are capable of potentiating the actions or enhancing the synthesis of neurotransmitters that promote increased neuronal activity $(51-53)$. There is some evidence that these short-term neuronal actions of $\mathrm{E}_{2}$ involve increased cAMP synthesis and activation of the cAMP-dependent protein kinase $(48,51,54)$, are stereo- selective $(48,54)$, and may $(48,49)$ or may not $(52)$ involve classical ERs. The upshot of these acute neuronal effects of $\mathrm{E}_{2}$ would be increased neuronal activity, which, in turn, is likely to be accompanied by vasodilation. In many cases, these effects of $E_{2}$ can be elicited with nanomolar doses. Thus, in the brain, the acute vasodilating actions of $E_{2}$ do not necessarily require direct interactions with vascular cells, but could occur indirectly, via actions on perivascular neurons.

\subsection{Chronic effects}

As a generalization, the vascular influence of chronic estrogen "exposure" is probably best characterized through a process resulting in potentiation of vasodilating capacity. To a large measure, that influence involves classical ERs, relates to genomic mechanisms (see earlier) and involves the regulation of proteins participating in vasodilation. The endothelium appears to be a major target for estrogen-related regulation of protein expression. In this regard, there are three candidates that merit consideration-eNOS and the proteins modulating its activity, cylooxygenases, and the proteins responsible for the production of endotheliumderived hyperpolarizing factors. Of those three, eNOS clearly has received the greatest attention in the literature, including studies on cerebral vascular tissue.

\subsubsection{Regulation of eNOS}

\subsubsection{Non-cerebral tissues}

Physiologic evidence: The enhancement of eNOS expression and function accompanying long-term estrogen exposure was initially revealed in studies on peripheral vascular tissue. Evidence in support of this can be derived from multiple sources. For example, arteries and arterioles harvested from female experimental animals exhibit a greater endothelium-derived NO generating capacity than their male counterparts in most (e.g., refs. 55-58), but not all (e.g., refs. 59, 60) instances. The absence of unanimity among published reports could relate to species-specific factors. In fact, in mice, the reverse situation was found, with the male rather than the female aorta displaying greater NO generation (60). However, the results of that particular investigation may still support an $\mathrm{E}_{2}$-related effect, since ER expression in the aorta is higher in the male versus the female mouse (60). Other possible examples of a linkage between chronic estrogen status and eNOS include reductions in the vasodilating actions of eNOS-dependent vasodilating stimuli, like acetylcholine or shear stress (61), following ovariectomy $(57,58,62)$ or after the onset of menopause $(63,64)$. That estrogen depletion specifically plays a key role in that diminished eNOS function is supported by results showing that the vasodilating responses could be restored with estrogen supplementation $(23,62)$. Consistent with these observations, chronic estrogen therapy 
in male to female transsexuals has been shown to enhance NO-dependent, acetylcholine (ACh)-induced vasodilations $(65,66)$. In pregnant animals, increased ACh-induced vasodilatory responses, which appear to parallel the rise in circulating estrogens, have been demonstrated in carotid and uterine arteries (67).

Regulation of eNOS expression: In line with the functional evidence given above, prolonged exposure to $E_{2}$ has been reported to be accompanied by increased eNOS protein or mRNA expression in peripheral vascular endothelium $(68,69)$ and in cultured endothelial cells $(70-72)$, via a process mediated by classical ERs (70). Thus, there is extensive evidence indicating that eNOS is a target for $\mathrm{E}_{2}$ in the periphery.

\subsubsection{Cerebral tissue}

Physiologic evidence: In the cerebral circulation, recent data (summarized in Table 1) would indicate that estrogen has an influence on eNOS similar to that seen in peripheral vascular tissue. Thus, long-term estrogen exposure in rats was found to promote a reduced myogenic tone, in subsequently isolated brain arteries, via an endothelium and NO-dependent process $(73,74)$. In another report, Palmon et al. (75) observed a direct correlation between microvascular cGMP levels in rats and prolonged increases in plasma $\mathrm{E}_{2}-\mathrm{a}$ finding that could be explained by, but does not prove, increased endothelial NO generation. Based upon such results, one might expect that intact and $E_{2}$-treated ovariectomized female rats would exhibit higher resting cerebral blood flow (CBF) levels compared to untreated ovariectomized rats. Curiously, no significant differences in global or regional CBF values have been noted among these groups in findings published to date $(1,76-78)$. Insofar as resting $\mathrm{CBF}$ is determined by multiple factors unrelated to NO, and factors capable of counteracting NO influence, the absence of any meaningful differences in basal CBF levels is not altogether surprising. On the other hand, chronic estrogen replacement therapy in postmenopausal human subjects was accompanied by a reduction in basal cerebrovascular resistance (79). Furthermore, resting $\mathrm{CBF}$ and $\mathrm{CBF}$ reactivity to vasodilating stimuli have been reported to be greater in female versus male subjects [reviewed by Hurn and McCrae (1)]. Unfortunately, no studies to date have addressed whether those observations are in any way related to NO.

A perhaps more striking example of the linkage between chronic estrogen status and eNOS function can be taken from studies where, instead of basal tone, responses to agoniststimulated eNOS-derived NO release were examined. Results from our laboratory revealed that chronic estrogen depletion, via ovariectomy, in rats was accompanied by a loss of eNOS-dependent (i.e., ACh-induced) vasodilating function in pial arterioles, but those changes could be

Table 1. Chronic estrogen "status" and possible eNOS-related changes in the brains of experimental animals

\begin{tabular}{|c|c|c|c|}
\hline Model & Estrogen status & eNOS-related result & Reference \\
\hline $\begin{array}{l}\text { Rat isolated middle } \\
\text { cerebral artery }\end{array}$ & $\begin{array}{l}\text { depleted } \\
\text { (ovariectomy) }\end{array}$ & $\uparrow$ myogenic tone & 73 \\
\hline $\begin{array}{l}\text { Rat isolated middle } \\
\text { cerebral artery }\end{array}$ & $\begin{array}{l}\text { repleted } \\
\left(\text { ovariectomy }+E_{2}\right)\end{array}$ & $\begin{array}{l}\downarrow \text { myogenic tone } \\
\text { (endothelium- and NO-dependent) }\end{array}$ & 73 \\
\hline $\begin{array}{l}\text { Rat isolated middle } \\
\text { cerebral artery branch }\end{array}$ & $\begin{array}{l}\text { depleted } \\
\text { (ovariectomy) }\end{array}$ & $\uparrow$ myogenic tone & 74 \\
\hline $\begin{array}{l}\text { Rat isolated middle } \\
\text { cerebral artery branch }\end{array}$ & $\begin{array}{l}\text { repleted } \\
\text { (ovariectomy }+E_{2} \text { ) }\end{array}$ & $\begin{array}{l}\downarrow \text { myogenic tone } \\
\text { (endothelium- and NO-dependent) }\end{array}$ & 74 \\
\hline Rat brain microvessels & $\begin{array}{l}\text { enhanced } \\
\text { (high-dose } E_{2} \text {-treated intact females) }\end{array}$ & $\uparrow$ cGMP content & 75 \\
\hline Rat pial arterioles in vivo & $\begin{array}{l}\text { depleted } \\
\text { (ovariectomy) }\end{array}$ & $\begin{array}{l}\text { loss of eNOS-dependent } \\
\text { vasodilation }\end{array}$ & 80 \\
\hline Rat pial arterioles in vivo & $\begin{array}{l}\text { repleted } \\
\left.\text { (ovariectomy }+E_{2}\right)\end{array}$ & $\begin{array}{l}\text { restoration of eNOS-dependent } \\
\text { vasodilation }\end{array}$ & 80 \\
\hline $\begin{array}{l}\text { Rabbit isolated middle } \\
\text { cerebral artery }\end{array}$ & $\begin{array}{l}\mathrm{E}_{2} \text {-treated, hyper-cholesterolemic } \\
\text { males }\end{array}$ & $\begin{array}{l}\text { restoration of eNOS-dependent } \\
\text { vasodilation }\end{array}$ & 38 \\
\hline Rat brain microvessels & $\begin{array}{l}\text { depleted } \\
\text { (ovariectomy) }\end{array}$ & $\downarrow$ eNOS protein expression & 82 \\
\hline Rat brain microvessels & $\begin{array}{l}\text { repleted } \\
\left(\text { ovariectomy }+E_{2}\right)\end{array}$ & $\uparrow$ eNOS protein expression & 82 \\
\hline Rat pial arterioles & $\begin{array}{l}\text { depleted } \\
\text { (ovariectomy) }\end{array}$ & $\downarrow$ eNOS, $\uparrow \mathrm{CAV}-1$ protein expression & 80 \\
\hline Rat pial arterioles & $\begin{array}{l}\text { repleted } \\
\left(\text { ovariectomy }+E_{2}\right)\end{array}$ & $\uparrow$ eNOS, $\downarrow$ CAV-1 protein expression & 80 \\
\hline
\end{tabular}


prevented with $1-2$ weeks of $E_{2}$ replacement (80). In a preliminary study (81), we also found that the changes in eNOS-dependent cerebral vasodilation associated with chronic estrogen status exhibited a regional selectivity, with results for the cortex and striatum, but not the hippocampus, mirroring those in pial arterioles (Fig. 1). Consistent with these findings, Ghanam et al. (38), reported that NO-dependent, ACh-induced relaxation of isolated rabbit middle cerebral arteries was enhanced when these animals were given chronic $\mathrm{E}_{2}$ treatment prior to vessel harvest.

Regulation of eNOS expression: Additional investigations, albeit limited in number (see Table 1), have examined the effects of chronic estrogen depletion and repletion on cerebral eNOS expression. The general conclusion from these studies is that, like most of the investigations directed toward peripheral vascular tissue (see above), chronic reductions in circulating estrogen (via ovariectomy) are associated with diminished cerebrovascular eNOS protein abundance, while $\mathrm{E}_{2}$ replacement restores eNOS $(80,82)$. The $E_{2}$-related effect on eNOS appears to exhibit a rather complex regional selectivity, with pial and striatal eNOS expression being reduced by ovariectomy and restored by $\mathrm{E}_{2}$ replacement, while in the hippocampus, no variations in eNOS were seen (Fig. 2). Those regional variations in eNOS abundance in most, but not all, cases mirrored the eNOS-related functional changes discussed in the preceding paragraph. The principal exception to this was the loss of eNOS-dependent vasodilating function in the cortex, following ovariectomy, despite no significant changes in eNOS abundance (Fig. 2). That apparent departure from

\section{intact}
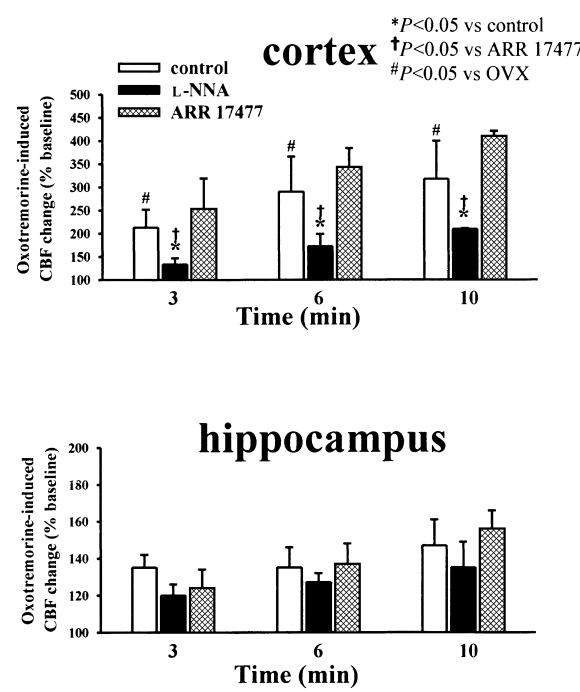

striatum

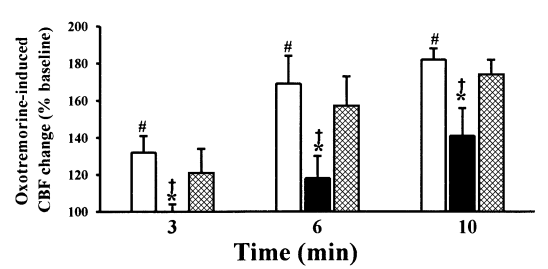

\section{OVX}

\section{cortex}
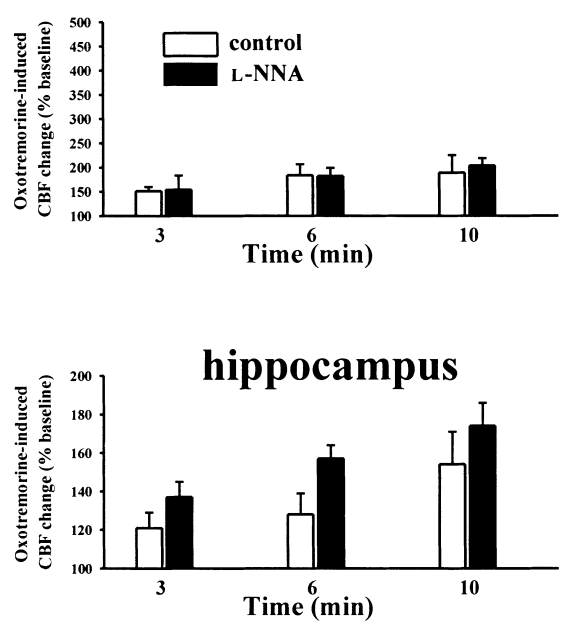

striatum

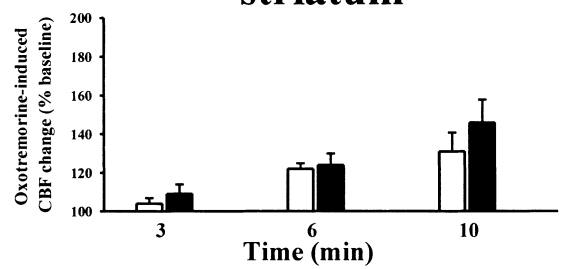

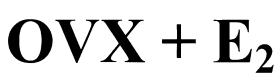
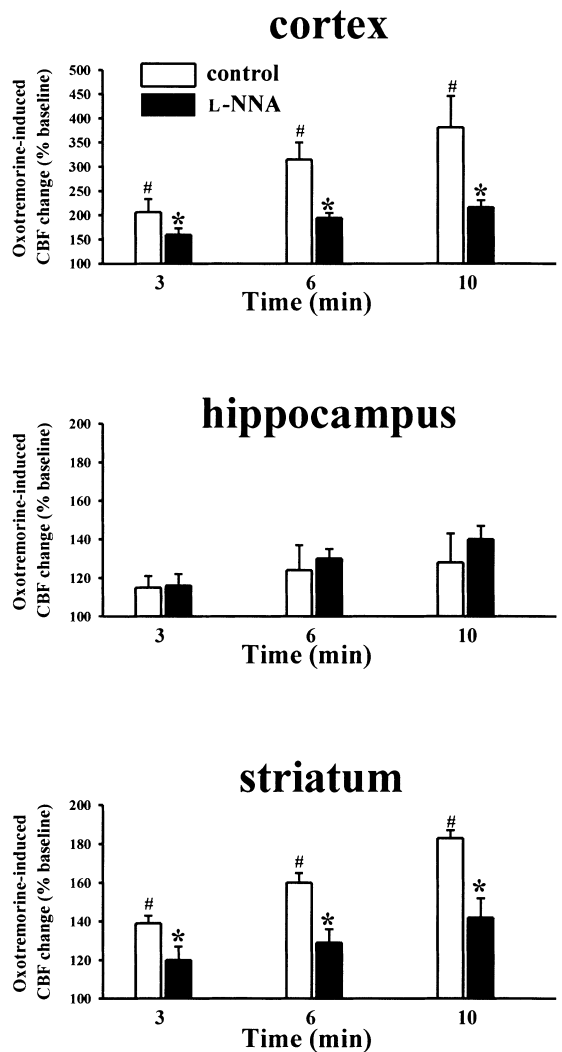

Fig. 1. eNOS-dependent vasodilating function in the cortex, hippocampus and striatum of intact, ovariectomized (OVX) and $\mathrm{OVX}+\mathrm{E}_{2}$-treated females. These studies, performed in fentanyl $/ \mathrm{N}_{2} \mathrm{O}$ anesthetized animals, used a $10 \mathrm{~min}$ i.v. infusion of the blood-brain permeant muscarinic agonist oxotremorine to elicit an eNOS-dependent vascular response (see refs. 190, 191). Changes in CBF were monitored using 3 laser-Doppler single fiber probes - two stereotactically inserted into the striatum and hippocampus, and one overlying the surface of the sensorimotor cortex (see ref. 78). In all 3 groups $(\mathrm{n}=5-6$ for each), the eNOS-dependent portion of the response was estimated by comparing results in the absence and presence of the non-specific NOS inhibitor, $N^{\mathrm{G}}$-nitro-L-arginine (L-NNA) $(10 \mathrm{mg} / \mathrm{kg}$, i.v.). The nNOS-independence of the oxotremorine response was demonstrated by the lack of any effect of the nNOS blocker, ARR 17477 (1 mg/kg, i.v.) (129). In cortex and striatum, but not hippocampus, there is an eNOS-dependent vasodilation that disappears in the absence of estrogen, to be recovered upon estrogen replacement. These observations reveal that estrogen can regulate the functional activity of brain eNOS, although regional differences exist. 


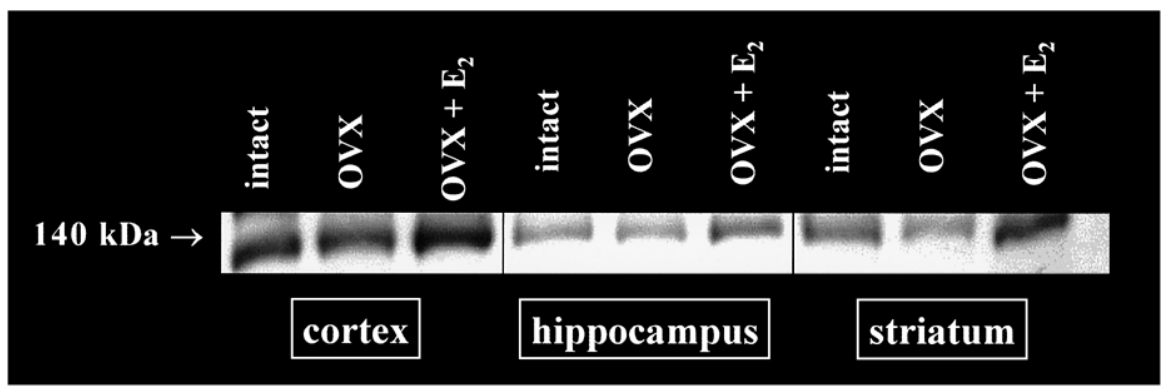

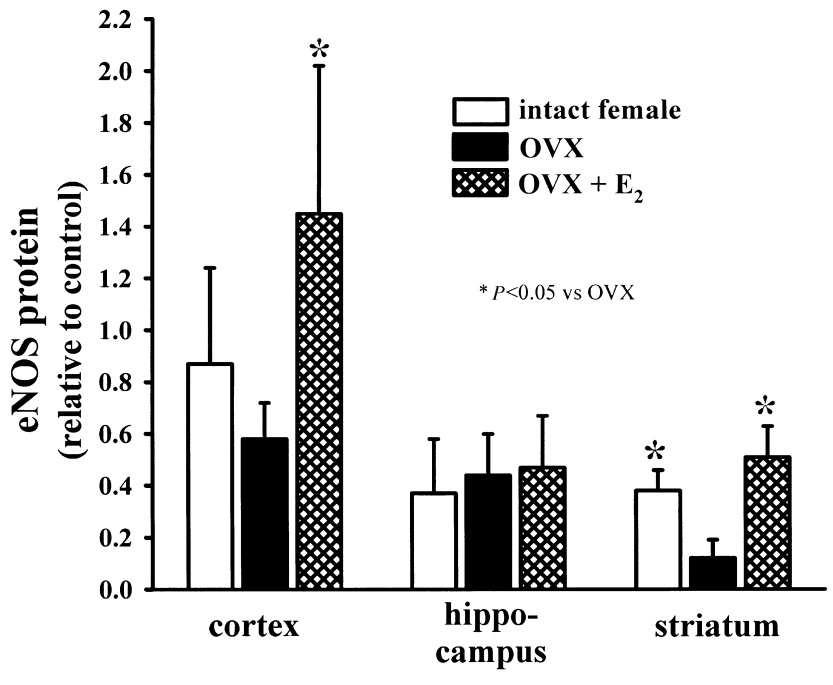

Fig. 2. Endothelial NOS (eNOS) protein expression [via Western immunoblotting, using a monoclonal antibody from Transduction Laboratories (80)] in the cortex, hippocampus and striatum of intact, ovariectomized $(\mathrm{OVX})$ and $\mathrm{OVX}+\mathrm{E}_{2}$-treated females (see refs. 78, 80, $177,178)$. In the lower panel, the levels of eNOS protein are expressed in relation to a HUVEC standard (control) run with each gel (not shown). The data for each group was taken from $4-5$ brains. In the striatum and, to a lesser extent, the cortex, but not hippocampus, expression of eNOS appears to correlate with the presence of estrogen. changes in eNOS function tracking eNOS protein expression may relate to a capacity for estrogen to modulate eNOS function via interactions with other endogenous eNOS-regulating substances. This is discussed further below.

Another conundrum revealed in these experiments is that the pattern of regional changes in eNOS abundance and functional activity did not correlate with the known regional patterns of classical ER expression. In fact, reports to date strongly indicate an absence of such receptors in the striatum $(83,84)$. On the other hand, based upon evaluations of labeled estrogen binding or mRNA analyses, ERs, especially the $\beta$-isoform, appear to be widely distributed in the hippocampus and cortex $(83-85)$. One rather intriguing implication of these findings is that estrogenassociated genomic regulation may operate via receptors and/or pathways that do not include the ER- $\alpha$ or ER- $\beta$ isoforms. Recent findings, in fact, provide some support for the presence of "alternative" ERs in the brain - receptors that are insensitive to established ER inhibitors or ER$\alpha$ or $-\beta$-selective ligands $(5,86)$. Whether such apparently novel receptors play a role in regulation of eNOS expression and function remains to be determined.

\subsubsection{Estrogen regulation of eNOS activity by indirect mechanisms}

Caveolin: It seems likely that the influence of chronic estrogen exposure on eNOS functional activity in the brain goes beyond simply modulating eNOS protein expression. Recent publications indicate that eNOS activity is regulated by a number of endogenous proteins. The best described among these is the plasma membrane protein, caveolin-1 (CAV-1), which binds to and acts as a potent negative regulator of eNOS activity in vascular endothelial cells $(87,88)$. Stimulation of eNOS occurs when $\mathrm{Ca}^{2+}$-activated calmodulin displaces CAV-1 from its binding site on the eNOS molecule. Caveolin-1, a $22-24-\mathrm{kDa}$ protein, is the major structural protein of endothelial cell plasma membrane invaginations called caveolae. Optimal sensitivity of eNOS to its endogenous activators requires its localization to caveolae. The importance of caveolar localization for efficient eNOS regulation may relate to the observation that most of the elements needed for activation of eNOS are concentrated in the microdomains of these structures. These include cofactors; L-arginine transporters (89); proteins regulating $\mathrm{Ca}^{2+}$ influx, extrusion and intracellular release (90); and even muscarinic receptors (91). In a recent publication, Feron et al. (92) found that upregulation of 
CAV-1 expression in non-cerebral endothelium (accompanying chronic elevations in free and LDL-cholesterol) was associated with an impairment in the ability to stimulate NO generation via eNOS. Thus, a precedent exists for a reduction in eNOS function in the absence of any changes in eNOS expression.

In pial vessels, we found that chronic estrogen depletion (ovariectomy) was associated with increased cerebral endothelial CAV-1 expression (80) (Fig. 3). That upregulation of $\mathrm{CAV}-1$ could be prevented with prolonged $\mathrm{E}_{2}$ supplementation (Table 1). Preliminary findings from our laboratory (93) indicated that this estrogen effect on CAV-1 could also be extended to include parenchymal microvessels (Fig. 3). The specific mechanisms through which $\mathrm{E}_{2}$ acts to reduce CAV-1 expression have not as yet been identified. Nevertheless, some interesting possibilities can be taken from the aforementioned studies on cholesterol and its influence on CAV-1 gene transcription in peripheral cells. Thus, via preventing transcription-repressing binding protein interactions with sterol response elements (SREs) on the CAV-1 promoter, free cholesterol can increase the formation of CAV-1 mRNA (94). On the other hand, oxysterols have been reported to potentiate binding protein interactions with SREs, thereby reducing CAV-1 gene transcription (95). Whether estrogen acts in brain in a manner similar to that of oxysterols is unknown. Another rather straightforward consideration is that estrogen influences CAV-1 expression in brain endothelium simply through its well-known cholesterol-lowering effect (see, for example, ref. 96). Those two possibilities should make interesting subjects for future study.

Heat shock protein 90 (hsp90): Although direct evidence is lacking, the results of a number of studies, showing separately that hsp90 can interact with both eNOS and estrogen receptors, hint at the possibility of hsp90 participating in estrogen regulation of eNOS function. For example, results from one report showed that the putative hsp90 inhibitor, geldanamycin, can interfere with ER function (97). This could impact on eNOS function, since ERs appear to be involved in both acute (40) and chronic (98) effects of estrogen on eNOS in cerebral vessels. Of additional relevance to the cerebral circulation, results from another study demonstrated that hsp90 inhibition elicited a substantial reduction in NOS-dependent vasodilation in isolated rat middle cerebral arteries (99). Nevertheless, whether such findings can truly be interpreted as estrogen modulating eNOS function in cerebral vessels via influences on hsp90 remains to be established experimentally.

Akt: The serine/threonine kinase, Akt (also called protein kinase $\mathrm{B}[\mathrm{PKB}])$, has been linked to eNOS activation $(100-102)$. The Akt kinase phosphorylates eNOS on serine 1177 , rendering eNOS far more sensitive to calmodulininduced activation (102). The major upstream activator of
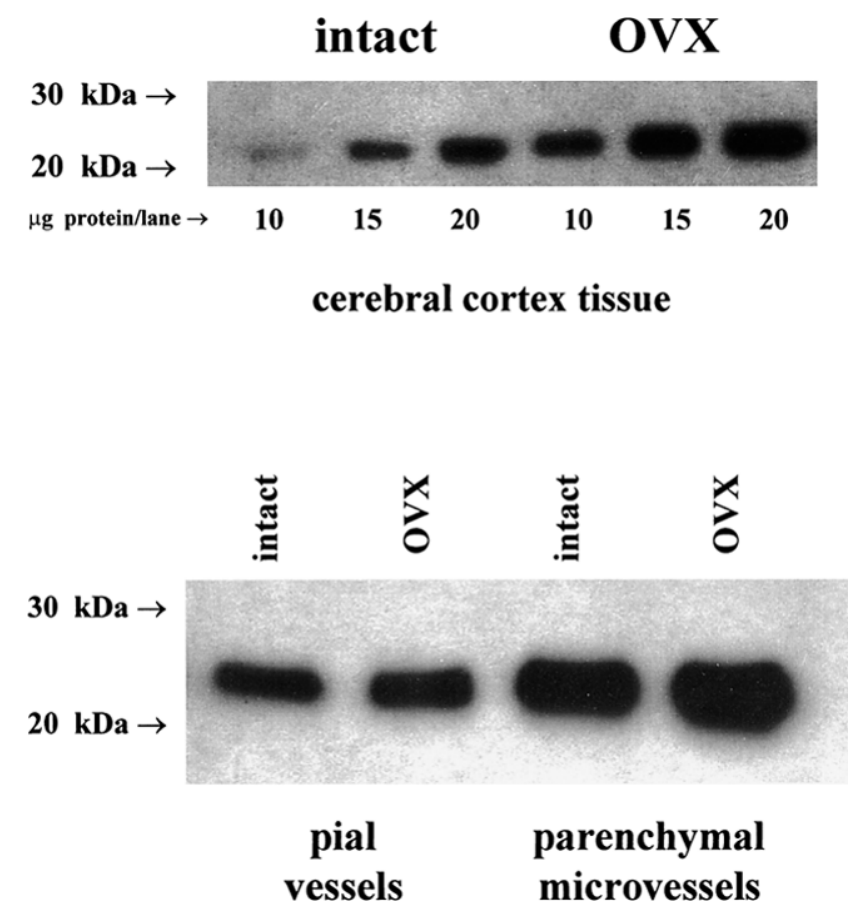

Fig. 3. Caveolin-1 (CAV-1) expression (Western immunoblots) in cerebral cortical tissue (upper panel) and in pial vessels or cerebral parenchymal microvessels (lower panel) harvested from intact and ovariectomized (OVX) female rats. The cortical immunoblots were taken from single intact and OVX animals, while for the pial and microvessel immunoblots, 3 rats were pooled in each group. The microvessels were prepared according to methods described by McNeill et al. (82). With the pial vessel analysis, the entire pial layer overlying the hemispheres was obtained. The linearity of the analysis is demonstrated in the upper panel, where protein loading was done at 10,15 and $20 \mu \mathrm{g} /$ lane for each group. For the pial vessels and parenchymal microvessels, $10 \mu \mathrm{g}$ protein/lane was loaded. A rabbit polyclonal antibody (from Transduction Laboratories) was used for this assay (80). In each case, the selectivity of the antibody was confirmed by the fact that only a single band (at $22-24 \mathrm{kDa}$ ) was visible. Pilot studies showed that the polyclonal antibody produced a far more robust reactivity than any of the monoclonal antibodies tested (e.g., m2297 or m2234 from Transduction Laboratories), indicating a higher affinity of the polyclonal vs the monoclonal forms, at least in tissue lysates, as the literature suggests (192). The major point emphasized in this figure is that depletion of estrogen induces the upregulation of CAV-1 in total brain tissue as well as invascular fractions isolated from pial membranes and the brain parenchyma. This evidence suggests that, in normal rats, the cerebrovascular expression of CAV-1 may be tonically repressed by chronic exposure to estrogen.

Akt appears to be phosphatidylinostitol 3-kinase (PI3-K), which is capable of phosphorylatying Akt at two serine /threonine sites (100). One mechanism for activation of PI3-K involves tyrosine kinase receptor-linked growth /trophic factors (100). That mechanism could be linked to estrogen by virtue of evidence provided in multiple studies showing that brain neurotrophin and tyrosine kinase receptor expression appear to vary directly with long-term estrogen changes $(103-106)$. Furthermore, $E_{2}$ was recently 
found to promote an ER-dependent, rapid, and sustained phosphorylation of Akt in neurons via a PI3-K-mediated process (101). While these particular mechanisms have not been confirmed in endothelial cells, it does suggest the possibility of yet another estrogen-associated influence on eNOS.

\subsubsection{Regulation of endothelial prostanoid release 3.2.2.1. Non-cerebral tissues}

Although the number of publications devoted to longterm estrogen influences on vasodilator prostanoid synthesizing capacity, compared to NO, are far fewer in number, some data are available. In peripheral vascular tissues, a majority of relevant publications point to a capacity for estrogen, over the long term, to enhance prostacyclin production $(107-110)$. The mechanism behind this $\mathrm{E}_{2}$ action may involve upregulation of vascular endothelial cyclooxygenase-1 (COX-1) expression $(108,109)$ and/or prostacyclin synthase (111). However, this action of estrogen may vary according to the vascular bed being studied. For example, increases in COX-1 expression or prostacyclin synthesis were seen in uterine $(107,111)$, aortic $(110)$, pulmonary (109) and umbilical (108) tissue, but not omental (107) and vascular tissue. In mesenteric vessels, one study reported $\mathrm{E}_{2}$ to be associated with a diminished prostanoid-dependent vasodilating function (112), while another provided evidence for an $\mathrm{E}_{2}$-related capacity to repress prostanoid-associated vasoconstrictor function (113).

\subsubsection{Cerebral tissue}

In the brain, reports on the effects of long-term estrogen depletion or supplementation are virtually absent from the literature. There is some evidence implying an estrogenlinked increase in brain prostaglandin $\mathrm{E}_{2}$ production or expression of the prostanoid receptor $(114,115)$. Also, findings from a recent study suggested that a capacity for estrogen to promote prostanoid-dependent vasodilation in cerebral arteries could only be revealed when NO production was inhibited (116). Clearly more work is needed before any conclusions can be made regarding long-term estrogen influence on prostanoid-dependent cerebral vasodilating function.

\subsubsection{Regulation of endothelium-derived hyperpolariz- ing factor in peripheral and cerebral tissue}

With respect to estrogen-related influences, of the three major endothelium-derived vasodilating factors, the endothelium-derived hyperpolarizing factor (EDHF) has received the least amount of attention. Results from two published reports indicated that the chronic estrogen elevations accompanying pregnancy were associated with increased release of a non-NO/non-prostanoid hyperpolarizing factor in mesenteric arteries (117) and aorta (118) when ACh was applied. On the other hand, in cerebral arteries, a seemingly opposite estrogen-related effect was observed. Thus, the contributions from a putative EDHF to ATP-induced dilations in the isolated rat middle cerebral artery were increased in ovariectomized rats relative to intact female rats (119). The possibility that the results of these studies reflect an organ-specific effect of estrogen on EDHF-mediated vasodilatory function cannot be established at this time, due to the limited nature of these data. Furthermore, the specific EDHF-related enzymes modulated by chronic estrogen changes are uncertain. In the aorta, circumstantial evidence points to an endothelial P450 epoxygenase product being involved (118). On the other hand, in the brain, the epoxygenases participating in the regulation of cerebrovascular tone (120) may be localized to astrocytes rather than endothelium (121). Thus, at least in the brain, the "endotheliumderived" label for a paracrine factor that elicits smooth muscle hyperpolarization may be too limiting. One implication of this is that, if estrogen indeed modulates expression of epoxygenases in the brain, the manifestation of that action may not be revealed in an isolated vessel. Moreover, the consistent and strikingly different effects of chronic estrogen changes in isolated cerebral vessels versus peripheral vessels may be suggestive of an estrogen influence on a non-epoxygenase, EDHF in cerebral arteries. Such issues need to be addressed in future studies.

\subsubsection{Endothelium-independent regulation of cerebral vasodilation}

\subsubsection{Role of the neuronal NOS}

The likelihood that estrogen may potentiate cerebral vasodilating function through regulation of protein expression in non-endothelial cells warrants some consideration. One particularly intriguing candidate is the other $\mathrm{Ca}^{2+}$-dependent NOS isoform found in the brain, the type I or neuronal NOS (nNOS). This isoform has received far less attention than eNOS, when considering estrogen-associated regulation. In the periphery, direct variations in nNOS mRNA and/or protein associated with long-term $\mathrm{E}_{2}$ treatment or depletion have been shown to occur in skeletal muscle (69), uterus $(122,123)$ and vaginal tissues (124). Significant increase in cerebellar NOS activity during pregnancy or following chronic $\mathrm{E}_{2}$ treatment have been observed in the guinea pig (69). However, the estrogen-associated enhancement of cerebellar nNOS activity may not necessarily relate to increased nNOS expression, but rather to an increase in calmodulin levels (125). Okamura et al. (126) showed a clear and positive effect of chronic $\mathrm{E}_{2}$ administration on NADPH diaphorase immunoreactivity (an indicator of nNOS) in rat hypothalamic neurons. Similarly, Rachman et al. (127) found an increase in hypothalamic nNOS mRNA following $E_{2}$ treatment. In the developing brain, the rise in brain NOS activity follows the same time course as the appearance of brain ERs (128). In that study and in 
the study of Weiner et al. (69), blockade of ERs with tamoxifen reversed the NOS upregulation. This suggests that the $\mathrm{E}_{2}$ effects on brain nNOS are mediated by ERs. Results from our laboratory also support a connection between chronic estrogen status and brain nNOS activity. We found that $\mathrm{Ca}^{2+}$-dependent NOS activity in the soluble fractions of cerebral cortical homogenates (a reflection of nNOS) varied according to the circulating $E_{2}$ level, with activities in ovariectomized rats approx. 50\% lower than those in intact or $E_{2}$-treated females (129). On the other hand, estrogen treatment has been associated with a downregulation of nNOS mRNA and protein in pituitary tissue an effect that may be specific to a particular splice variant of nNOS (130). However, these findings could also be explained on the basis of a regional selectivity in estrogen regulation of nNOS, although that possibility has yet to be confirmed.

\subsubsection{Role of the cholinergic system}

Changes in the levels of estrogen have also been linked to variations in the expression of enzymes responsible for the synthesis of vasodilating neurotransmitters, as well as the expression of receptors participating in vasodilating responses. One of the best-studied of these neurotransmitter pathways is the muscarinic cholinergic system. Certainly, the connection between this neurotransmitter system and endothelium- and eNOS-dependent vasodilation is wellestablished. However, in the present context, we will expand this to include endothelium-independent mechanisms like muscarinic receptor-mediated neuronal activation. One of the most important clinical implications arising from a potentiating influence of estrogen on this system is a reduction in the incidence and severity of Alzheimer's disease symptoms (e.g., ref. 131). There may be several sites for estrogen control of cholinergic function. The first relates to the rate-limiting enzyme in the ACh biosynthetic pathway - choline acetyltransferase (ChAT). Thus, the expression ChAT message and protein, especially in neurons of the basal forebrain, have been found to vary directly with estrogen status $(132-134)$. Estrogen has also been reported to be associated with increased muscarinic receptor sensitivity to agonist-induced activation (135) and diminished potency of muscarinic receptor antagonists (136). The hippocampus appears to be particularly sensitive to these effects (136). Other investigators have reported an estrogen-related increase in the number of muscarinic receptors $(137,138)$, although such changes may be confined to the hypothalamus (137) and, therefore, may have little relevance to overall circulatory control. An absence of estrogen-associated changes in muscarinic receptor abundance was supported by preliminary findings from our laboratory (unpublished) indicating no differences in cerebral cortical, striatal or hippocampal arterial/arteriolar muscarinic receptor expression in intact versus ovariectomized rats. Never- theless, even in the absence of changes in receptor numbers, one might consider the possibility that the loss and restoration of muscarinic agonist-induced cerebral vasodilation accompanying chronic estrogen depletion and repletion, respectively (discussed earlier), may be more than just a simple function of changes in eNOS and CAV-1 expression.

\subsubsection{Role of synaptic remodelling}

Another documented phenomenon associated with prolonged (i.e., $\geq 24 \mathrm{~h}$ ) estrogen exposure is increased brain synaptic density (see, for example, refs. 139, 140). Since the extent of synapse density and neuronal connectivity has been linked to the level of brain perfusion (e.g., ref. 141), it is tempting to suggest that estrogen-associated synaptogenesis may provide an additional mechanism for improving cerebral vasodilating function. From findings obtained in rats, two brain regions, the CA1 sector of the hippocampus and the ventromedial hypothalamus (VMH), appear to be particularly sensitive to estrogen-related increases in synapse density, as evidenced by increased formation of dendritic spines. In the hippocampus, the density of dendritic spines on $N$-methyl-D-aspartate (NMDA) receptor-expressing synapses have been found to vary with changes in estrogen levels (139). In the VMH, circumstantial evidence implies similar changes, but direct confirmation is lacking (140). Whether synaptogenesis-associated expression of other neurotransmitter receptors, with links to vasodilation, are similarly increased by estrogen, remains to be established. Cyr et al. (142) recently reported that estrogen exhibits a regional heterogeneity in its influence on NMDA receptor density, with increases seen for the hippocampus (CA1 and dentate gyrus), but reductions observed in the striatum and frontal cortex. The link between activation of NMDA receptors and cerebral vasodilation, via a process that is largely dependent upon nNOS-derived $\mathrm{NO}$, is well-established in many brain regions, including the hippocampus (143). Nevertheless, although estrogen may increase NMDA receptor numbers in some brain regions, estrogen has also been associated with diminished NMDA receptor activity (144). This may limit the overall impact of estrogen-induced increases in NMDA receptor expression on cerebral vasodilating function.

\subsubsection{Role of noradrenaline and adenosine}

Independent from factors related to synaptic remodeling, other vasodilating neurotransmitter/neuromodulator candidates, that merit consideration as potential targets of estrogen influence, are norepinephrine (NE) and adenosine. Compared to the body of information related to cholinergic mechanisms, the literature regarding long-term estrogen influence on cerebral adrenergic or adenosinergic systems is sparse. There is some evidence of a positive estrogen effect on the expression of tyrosine hydroxylase (the ratelimiting enzyme in the synthesis of NE) in cortical neurons 
(145). The results of another study indicated that estrogen can potentiate NE responses (cAMP accumulation) in brain neurons, with $\alpha_{2}$, rather than $\beta$-adrenoceptors, being affected (146). Activation of $\alpha_{2}$-adrenoceptors has been shown to elicit an endothelium-dependent cerebral vasodilation, via receptors present on the vessels themselves (147), but there is no information as to whether estrogen influences vascular adrenoceptors. With respect to adenosine, estrogen has been linked to increased cerebral activity of the enzyme responsible for adenosine synthesis - 5'-nucleotidase (148). However, there is no currently available data as to whether estrogen influences the expression or activity of adenosine synthesis, degradation or receptor proteins in vascular cells.

\section{Estrogen and cerebrovascular inflammation}

The discussion up to this point has dealt with estrogen control of vascular function within normal physiologic boundaries. In this section, the focus will be on how estrogen can modulate the changes in vascular function occurring under pathologic conditions. The inflammatory reactions accompanying a number of pathologic states can lead to the localized upregulation of proteins mediating the production of potent vasodilating substances as well as locally-damaging reactive oxygen species. There is a growing body of information linking inflammation and inflammatory proteins to the brain cell damage associated with neurodegenerative brain diseases, brain and spinal cord trauma, and stroke (for a review, see ref. 149). The number of inflammatory proteins that might participate in neuropathologic changes is extensive. For the purpose of simplification, the present discussion will be limited to only a few proteins, where some connection to estrogen has been identified. Examples include cytokines, adhesion molecules, iNOS and cyclooxygenase-2 (COX-2).

\subsection{Inflammatory events in endothelial cells}

As a generalization, the process of inflammation is initiated principally in post-capillary venules through enhanced interactions between receptor-ligand pairs on both leukocytes and vascular endothelial cells. Leukocyte capture and rolling comprise the first phase of this process (150). This stage is mediated primarily by the selectin family of adhesion molecules. The principal member of this family is the endothelial P-selectin, which facilitates rolling through interactions with its counter-ligand, P-selectin glycoprotein ligand-1 (PSGL-1), on leukocytes (151). Other selectins, such as the endothelial E-selectin, may play a role in further slowing leukocyte rolling velocity, thereby increasing the interaction between leukocytes and locally-produced inflammatory mediators (e.g., cytokines, chemokines - see below). Subsequent firm adhesion and sticking is mediated by the interaction between leukocyte $\beta$-integrins and intercellular and vascular cell adhesion molecules (ICAM-1, ICAM-2, VCAM-1) on the endothelial surface. This process is facilitated by the presence of cytokines, like interleukin-1 $\beta$ (IL- $1 \beta$ ) and tumor necrosis factor $\alpha$ (TNF- $\alpha$ ), and local chemoattractants (149). The last step in the adhesion cascade is leukocyte transendothelial migration and involves, among other factors, the participation of an adhesion molecule present in both endothelium and leukocytes (i.e., PECAM-1).

\subsection{Effect of estrogen on inflammation in non-cerebral endothelium}

In peripheral tissues, with few exceptions (see, for example, ref. 152), most of the data obtained from human subjects and experimental animals point to an estrogen-related limitation in the expression of adhesion molecules under basal conditions and following pro-inflammatory stimuli. Several studies have indicated counter-inflammatory actions accompanying short-term (15 minutes to several hours) estrogen exposure, as evidenced by reduced post-ischemic leukocyte accumulation in cardiac and mesenteric tissue (153). The relatively short time frame of estrogen exposure, especially over periods of less than one hour, implies the participation of mechanisms apart from direct estrogen modulation of adhesion molecule transcriptional activity. One possibility is a restriction in the mobilization of constitutively-expressed adhesion molecules from intracellular reservoirs to their sites of action on the cell surface. A potential candidate is $\mathrm{P}$-selectin, which under resting conditions, is present in intracellular storage granules (WeibelPalady bodies) (154). The secretion of Weibel-Palady bodies has been reported to be inhibited by NO (e.g., ref. 155). Therefore, one might consider that estrogen's acute counter-inflammatory effects relate, as described earlier, to an increase in NO generation via stimulation of a constitutive NOS (156). However, an increase in the levels of NO, when extended over periods of several hours, may also limit adhesion molecule expression (157).

In conjunction with long-term ( $\geq 1$ day) estrogen exposure, cultured human umbilical vein, saphenous vein or rabbit aortic endothelial cells displayed a decreased expression of E-selectin, ICAM-1 or VCAM-1 following cytokine, LPS or lysophosphatidylcholine treatment $(158-160)$. In human subjects, circulating levels of adhesion molecules were found to be lower in postmenopausal females receiving estrogen replacement therapy, compared to their untreated counterparts (161). These results support a genomic action of estrogen, perhaps via blocking the transcription of adhesion molecules (158).

Because of the evidence that estrogen up-regulates the expression and/or the activity of constitutive NOS's and the evidence that NO has anti-adhesive properties, it is 
tempting to ascribe the anti-inflammatory effects of estrogen to an enhancement of NO generation within the submicromolar ranges attributable to eNOS and nNOS. Changes in leukocyte adhesion and adhesion molecule expression accompanying administration of NOS inhibitors or NO donors have been widely observed, both under basal conditions and in association with ischemia/reperfusion (162 167). Furthermore, an increase in mesenteric leukocyte adhesion was recently observed in both eNOS and nNOS knock-out mice (168). These findings demonstrated the anti-adhesive capabilities not only of the NO produced at the endothelium, which is ideally situated to influence both endothelial and leukocyte adhesion molecule expression, but also of nNOS-derived NO. These studies suggest, therefore, that at least a portion of estrogen's capacity to reduce leukocyte adhesion may be related to stimulation of constitutive NOS activity, either eNOS or nNOS. Relevant to this discussion, Garcia-Duran et al. (169) showed that estrogen stimulates nNOS protein expression in human neutrophils. This was associated with a reduction in the expression of the CD18 integrin on the surface of $\mathrm{E}_{2}$-incubated neutrophils, producing a decrease in adhesive capacity.

\subsection{Counter-inflammatory effects of estrogen: role of NF $\boldsymbol{K} \mathbf{B}$}

At the molecular level, the purported ability of estrogen to interfere with the adhesion process may be due to blocking $\mathrm{NF} \kappa \mathrm{B}$ activation (170). NF $\kappa \mathrm{B}$ is widely accepted as a central transcription factor in inflammation. Its activity is regulated by inhibitory proteins such as $\mathrm{I} \kappa \mathrm{B}-\alpha$. Evidence to date indicates that modulation of $\mathrm{I} \kappa \mathrm{B}$ degradation and /or synthesis is indeed a common mechanism in the regulation of $\mathrm{NF} \kappa \mathrm{B}$ activity (170). The $\mathrm{I} \kappa \mathrm{B}$ proteins bind to $\mathrm{NF} \kappa \mathrm{B}$ dimers, thus stabilizing them in the cytoplasm of resting cells. When cells are exposed to inflammatory agents, like cytokines, I $\kappa$ Bs are phosphorylated at serine residues by $\mathrm{I} \kappa \mathrm{B}$-kinases. That action targets these proteins for ubiquitination and degradation by proteosomes. This releases $\mathrm{NF} \kappa \mathrm{B}$ and exposes a nuclear localization signal, which leads $\mathrm{NF} \kappa \mathrm{B}$ to the nucleus, where it binds to sites in gene promoters, usually triggering transcription. Most of the genes encoding for cell adhesion molecules have $\kappa \mathrm{B}$ binding sites in their promoters. The fact that $\mathrm{NF} \kappa \mathrm{B}$ is ubiquitous, responds to a wide variety of pathogenic signals and functions as a pleiotropic inducer of transcription supports the central role that this factor plays in inflammation. Estrogen influence on NF $\kappa \mathrm{B}$ may involve both NOdependent and -independent actions. With respect to the former and estrogen's known capacity to enhance constitutive NO generation, there is a reasonable body of evidence indicating that $\mathrm{NO}$ can reduce $\mathrm{NF} \kappa \mathrm{B}$ function in multiple cells, endothelial cells in particular, via influences on $\mathrm{I} \kappa \mathrm{B}$. The exact mechanism is unclear, but it may involve trans- criptional induction of $\mathrm{I} \kappa \mathrm{B}(170)$ and/or prevention of $\mathrm{I} \kappa \mathrm{B}$ degradation (171). That action of NO may be a function of its ability to behave as an antioxidant (172), since oxidative stress is one of the major triggers for $\mathrm{NF} \kappa \mathrm{B}$ activation (173). There is also evidence to indicate that estrogen (via interactions with its receptor [174]), without invoking any contributions from NO, may repress the transcriptional activation of adhesion molecules via preventing the degradation of $\mathrm{I} \kappa \mathrm{B}-\alpha$ and maintaining $\mathrm{NF} \kappa \mathrm{B}$ in its inactive form (175). Also, estrogen, by virtue of its rather potent antioxidant properties (176), could contribute to the prevention of oxidative stress-induced NF $\kappa$ B activation (173). Nevertheless, although estrogen-associated repression of inflammation appears to include actions toward $\mathrm{NF} \kappa \mathrm{B}$, current evidence does not permit one to dismiss the possibility that estrogen may act to prevent adhesion molecule transcription via mechanisms (receptor-dependent?) not involving $\mathrm{NF} \kappa \mathrm{B}$.

\subsection{Effect of estrogen on inflammation in cerebral tissue 4.4.1. Effect on adhesion molecule expression}

Studies addressing the effects of estrogen on cerebral inflammatory mechanisms are relatively few in number. Results from our own laboratory revealed that chronic estrogen depletion increased basal and PKC-stimulated leukocyte adhesion in pial venules, with those changes being reversible in the presence of chronic $E_{2}$ replacement (177). In another study, we observed that the increase in pial venular leukocyte adhesion, during the reperfusion period following forebrain ischemia, was influenced by chronic estrogen status (178). In that investigation, no differences in the extent of leukocyte adhesion, when comparing intact, ovariectomized, and $E_{2}$-treated ovariectomized females, were observed at $2 \mathrm{~h}$ of reperfusion. However, when the reperfusion time was extended to 4 and $6 \mathrm{~h}$, the level of leukocyte adhesion in the intact and $E_{2}$-treated, but not untreated, animals declined substantially from the $2 \mathrm{~h}$ level. That reduction in the number of adherent leukocytes could not be attributed to de-adhesion and subsequent tissue infiltration, since no leukocytes were seen within the brain parenchyma at $6 \mathrm{~h}$ of reperfusion. Although the specific mechanisms are not known, these results suggest a process whereby estrogen promotes de-adhesion, allowing leukocytes to return to the circulation. The absence of any signs of leukocyte infiltration in this study was not completely unexpected, since, in forebrain ischemia, leukocyte infiltration does not occur until about $24 \mathrm{~h}$ of reperfusion. Furthermore, chronic estrogen depletion appears not only to potentiate, but also to to accelerate the process of post-ischemic diapedesis. That is, preliminary findings from our laboratory (Fig. 4) indicated a substantial degree of leukocyte infiltration already at $12 \mathrm{~h}$ of reperfusion in ovariectomized rats, as opposed to a virtual absence of infiltrated leukocytes in intact females. 
The mechanisms responsible for the estrogen-related repression in leukocyte adhesion in cerebral vessels has not as yet been clearly defined. It is tempting to ascribe these effects to the same mechanisms modulating inflammatory processes in peripheral vascular tissue. One possibility relates to the ability for estrogen to upregulate both eNOS and nNOS expression and activity in the brain, as discussed earlier. That NO may play an anti-adhesive role in the cerebral circulation was shown in a recent paper by Hudetz et al. (179). In that study, administration of an NOS inhibitor, L-NAME, just prior to reperfusion in rats subjected to forebrain ischemia, was associated with an increase in the level of leukocyte adhesion normally seen over $60 \mathrm{~min}$ of reperfusion. However, a recent preliminary study from our laboratory (180) revealed that the chronic absence of NO production in brain did not increase adhesion molecule expression in parenchymal microvessels, at least under resting (non-ischemia/trauma-associated) conditions. This result runs contrary to evidence in peripheral circulation where chronic inhibition of basal release of NO induces adhesion molecule expression (181), indicative of a tonic anti-inflammatory role of NO. One might speculate that the different findings in cerebral parenchymal (180), compared to peripheral (181), vascular tissue are due to the existence of NO-independent, yet estrogen-sensitive, counter-inflammatory processes in the former, at least with respect to resting, non-pathologic states. We do not, however, view our findings in parenchymal vessels as contradictory to the results of Hudetzet al. (179) in pial vessels, since those authors monitored leukocyte adhesion following an ischemic insult.

\subsubsection{Effect on the inducible nitric oxide synthase and other inflammatory proteins}

Data obtained to date in studies on peripheral vascular tissues would suggest that estrogen is capable of restricting the upregulation of iNOS elicited by inflammatory stimuli $(68,182)$. On the other hand, simple $\mathrm{E}_{2}$ exposure $(1-2$ days $)$ was found to increase the expression of iNOS in rat aorta (183) and in cultured endothelial cells (184). However, since these latter data were obtained under conditions not associated with inflammation, their relevance to the present discussion is limited.

In the brain, preliminary findings from our laboratory appear to support a mechanism whereby estrogen acts to prevent iNOS upregulation under conditions of increased inflammatory activity. That is, detectable iNOS immunoreactivity, at $24-72 \mathrm{~h}$ following forebrain ischemia, was observed only in ovariectomized females and not in $\mathrm{E}_{2}-$ treated or intact females (Fig. 5). Multiple cell types were found to express iNOS at $72 \mathrm{~h}$. The major iNOS-expressing cells appeared to be intraparenchymal polymorphonuclear leukocytes and monocytes/macrophages. Some iNOS expression was also observed in endothelium and in cells resembling activated microglia (not shown). The observation that such expression was minimal in post-ischemic

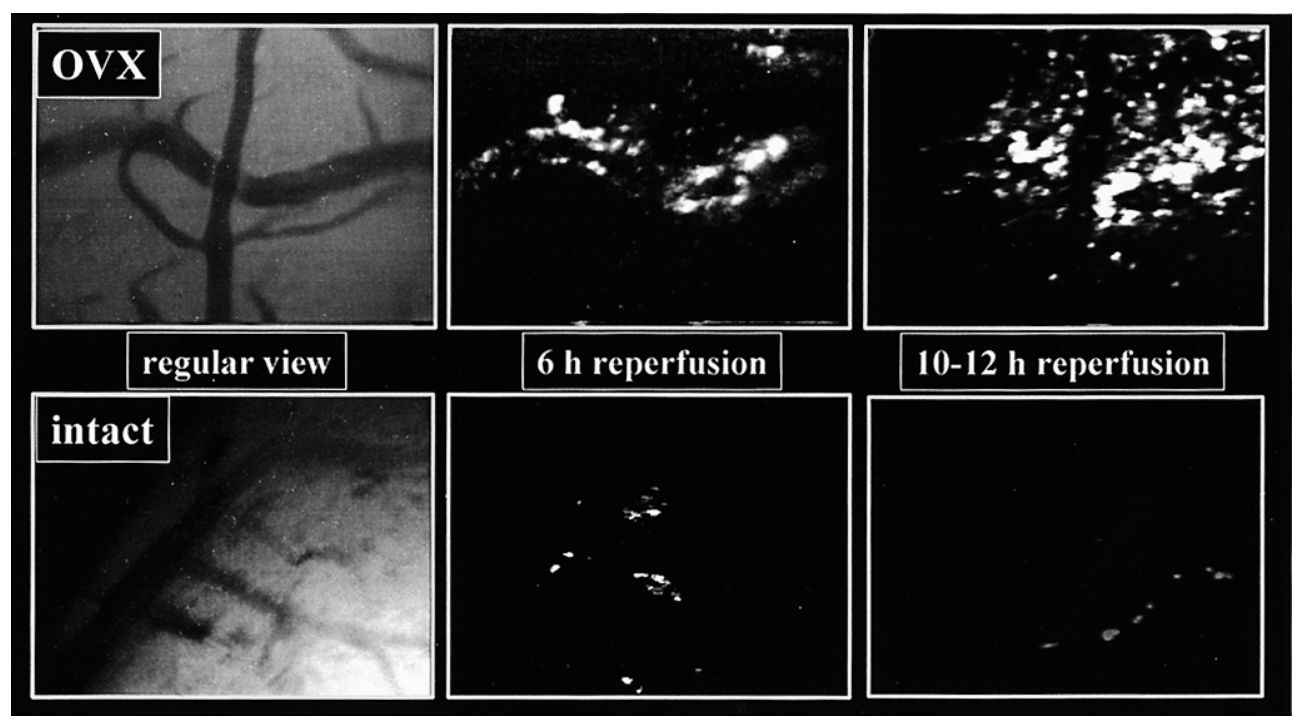

Fig. 4. Actual frames captured from video recordings of leukocyte adhesion at $6 \mathrm{~h}$ and $10-12 \mathrm{~h}$ reperfusion following $30 \mathrm{~min}$ of transient forebrain ischemia in an ovariectomized (OVX) vs an intact female rat. Adherent rhodamine-6G-labeled leukocytes (white and gray "spots") were viewed through a closed cranial window, using intravital fluorescence microscopy, according to procedures described in earlier publications from our laboratory $(177,178)$. Note, in images captured during the experiments reported in ref. 178, the far greater magnitude of leukocyte adhesion in the OVX vs intact rat at $6 \mathrm{~h}$ reperfusion. In several rats (data not previously reported), the period of observation was extended out to $10-12 \mathrm{~h}$. Note the extensive leukocyte infiltration into the parenchyma at $10-12 \mathrm{~h}$ in the OVX rat and the absence of infiltration in the intact rat. Also shown - pial venules under standard light. Note that vertically-oriented arteriole in the OVX rat is devoid of adherent leukocytes. 
brains taken from intact and $\mathrm{E}_{2}$-treated ovariectomized females certainly adds to the body of evidence favoring a counter-inflammatory estrogen action in the brain.

The iNOS upregulation is likely to be accompanied by prolonged localized increases of NO in micromolar quantities. Nevertheless, by itself, NO is not likely to cause any substantial cellular damage. The cytotoxic actions of iNOSderived NO probably derive from the rapid, diffusion-limited reaction between $\mathrm{NO}$ and superoxide radical to form the potent pro-oxidant, peroxynitrite (185). We have obtained evidence of extensive peroxynitrite generation (as indicated by measurements of nitrotyrosine expression) in brains obtained from ovariectomized females at $72 \mathrm{~h}$ following forebrain ischemia (Fig. 6). That apparent increase in postischemic peroxynitrite generation requires both a source for NO (seemingly provided by iNOS) and for superoxide radical. One likely superoxide source is the NADPH oxidase present in activated leukocytes and microglia. Another possible source is cyclooxygenase, the inducible COX-2 isoform in particular. Like iNOS, COX-2 can also be labeled as an inflammatory protein (149), and it is known to be upregulated following forebrain ischemia (186). Although no studies have addressed whether estrogen influences cerebral COX-2 expression, estrogen has been associated with reduced COX-2 expression in peripheral tissues (187). Furthermore, COX-2, as well as iNOS, induction in the brain appear to involve NF $\kappa \mathrm{B}$ activation (188). Since estrogen has been linked to repression of $\mathrm{NF} \kappa \mathrm{B}$ activity (see earlier), it would not be altogether surprising to find that post-ischemic expression of COX-2, like iNOS, will vary inversely with chronic estrogen status.

In our experiments, only limited signs of peroxynitrite formation were seen in estrogen-repleted or intact females (Fig. 6). In the same rats displaying enhanced iNOS and nitrotyrosine expression, there was evidence of substantial lipid peroxidation - an indicator of oxidative damage. Moreover, much of the lipid peroxidation was concentrated in vascular endothelial cells (Fig. 7). No signs of lipid peroxidation were observed in intact or $\mathrm{E}_{2}$-treated rats. Thus, one manifestation of estrogen's counter-inflammatory effects in the brain appears to be vascular endothelial protection. In support of this, recent findings have shown that chronic estrogen exposure can block the cerebral vascular damage induced by amyloid $\beta$-protein (189).

A composite illustration of the suggested mechanisms involved in estrogen's counter-inflammatory actions in cerebral endothelial cells is presented in Fig. 8. The figure represents a speculative synthesis of experimental evidence obtained in both cerebral and non-cerebral vascular tissue (see earlier). The principal emphasis is on estrogen's ability to disrupt the inflammatory cascade unleashed following a cerebral insult like ischemia and reperfusion. Figure 8 also considers $\mathrm{NF} \kappa \mathrm{B}$ as a major target of estrogen actions and

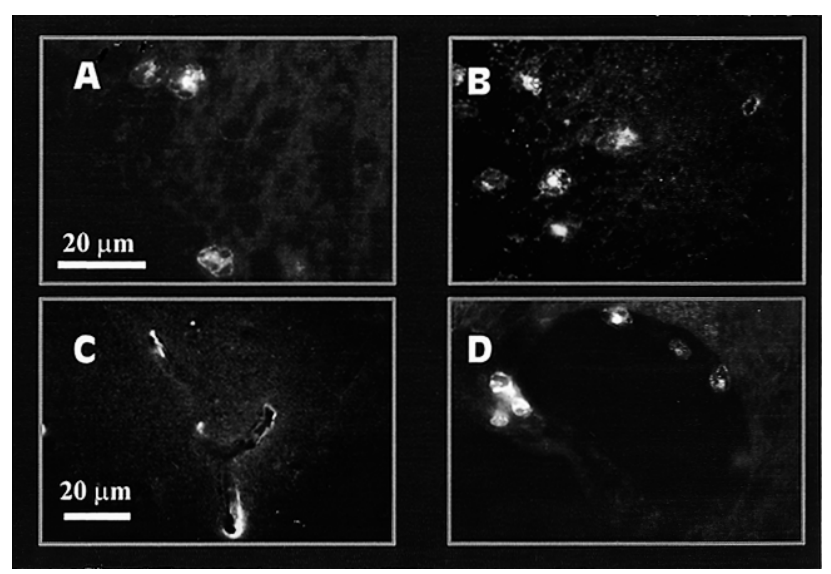

Fig. 5. Inducible NOS (iNOS) immunofluorescence at $72 \mathrm{~h}$ postischemia in ovariectomized (OVX) females in cells within the brain parenchyma of the striatum (A) and hippocampus (B), in endothelium (C) and in cells embedded in endothelium (D). Few or no iNOS immunoreactive cells were observed in intact or $\mathrm{E}_{2}$-treated OVX rats (not shown). For this analysis, we used $7-\mu \mathrm{m}$ coronal sections of paraformaldehyde-fixed and paraffin-embedded rat brains, obtained in an earlier investigation (78). A rabbit polyclonal anti-iNOS antibody (from Transduction Laboratories) was employed. FITC was used as the fluorophore (see ref. 80). The scale marker, shown in panel A, applies to panels A and B. The scale marker presented in panel $\mathrm{C}$ applies to panels $\mathrm{C}$ and $\mathrm{D}$.

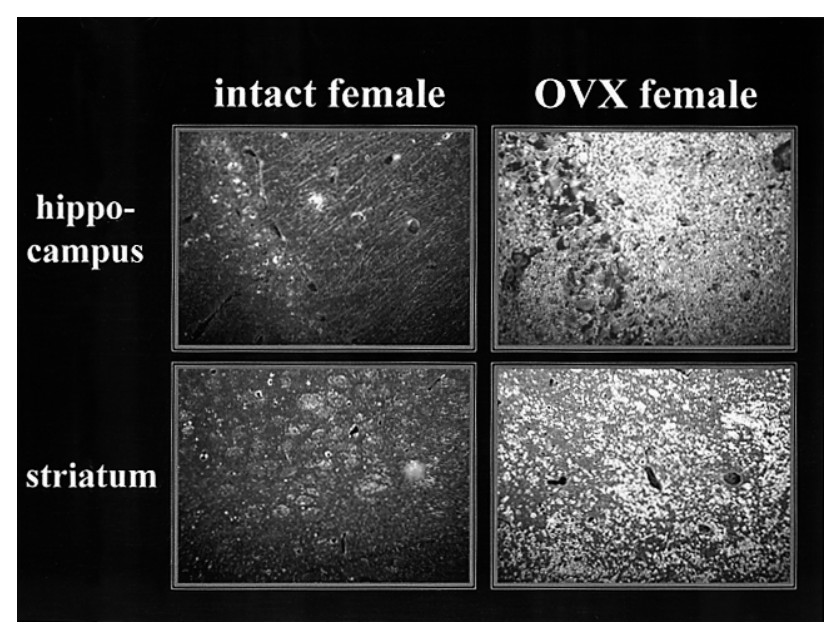

Fig. 6. 3-Nitrotyrosine immunofluorescence (a measure of $\mathrm{ONOO}^{-}$ generation) at $72 \mathrm{~h}$ post-ischemia in the hippocampus (upper panels) and striatum (lower panels) of intact (left panels) vs ovatiretomized (OVX) (right panels) female rats. Seven-micrometer coronal sections were prepared from paraformaldehyde-fixed and paraffin-embedded rat brains obtained in an earlier investigation (78). A rabbit polyclonal anti-3-NT antibody (from Upstate Biotechnology) was employed. $\mathrm{Cy}^{3}$ was used as the fluorophore (see ref. 80). Note the far greater intensity of 3-NT expression in the OVX rats.

also places some emphasis on estrogen's purported capacity to upregulate eNOS and to restrict oxidative activity. 


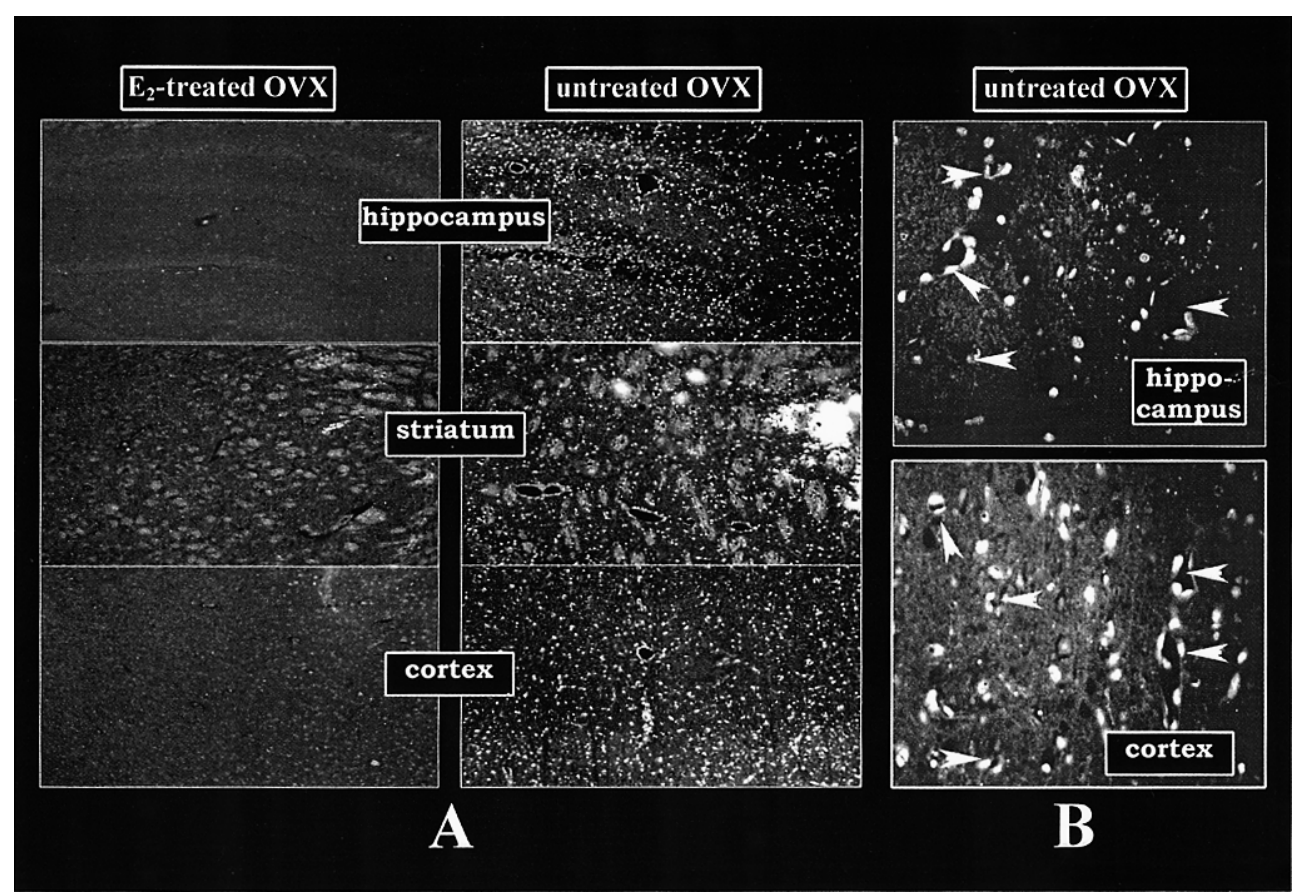

Fig. 7. Malondialdehyde (MDA)-modifed protein immunofluorescence (a measure of lipid peroxidation) at $72 \mathrm{~h}$ post-ischemia in the hippocampus, striatum and cortex of $\mathrm{E}_{2}$-treated vs untreated ovariectomized (OVX) female rats. Seven-micrometer coronal sections were obtained from paraformaldehyde-fixed and paraffin-embedded rat brains, as previously described (80). A polyclonal (rabbit) antibody (see ref. 193) was used for this analysis, with FITC as the fluorophore. A) Low magnification. B) Higher magnification showing expression concentrated in endothelial cells (examples indicated by arrowheads).

\section{Concluding remarks}

The broad spectrum of actions linked to estrogen are probably a reflection of multiple sites and pathways of $\mathrm{E}_{2}$ influence. That wide range of estrogen effects, on the one hand, may be a principle reason for its vasculoprotective efficacy. On the other hand, the complex pattern of estrogen's influence may also contribute to the rather substantial disparity in published findings with respect to specific mechanisms of estrogen action. One factor not covered in this review is the influence of progesterone - the other major female sex steroid. Multiple studies have been published indicating that progesterone can reverse or prevent many of the actions of estrogen described in this review. Other reports, only touched upon in the present paper, have hinted at the possibility that the vascular influence of estrogen treatment may be less pronounced in males. Thus, the manner in which a vessel or vascular cell responds to estrogen may depend, among other things, upon the presence of progesterone, gender, the duration of estrogen exposure, the dose, the vascular bed, vessel size or segment, whether that tissue is studied in vivo or in vitro, or species. Despite these "complications", our understanding of how estrogen influences vascular cells continues to expand. However, our quest to gain insight into the mechanisms involved in estrogen's effects on cerebral vessels is still in the early stages. Obviously, more research in this area is needed.

\section{Acknowledgments}

The authors wish to thank Dr. Shuhua Ye, Dr. Roberto Santizo, Dr. Douglas Feinstein, Dennis Riley and Susan Anderson for their indispensible contributions to this review. The work was supported by grants HL 56162 and HL 59594 from the National Institutes of Health, USA.

\section{REFERENCES}

1 Hurn PD and McCrae IM: Estrogen as a neuroprotectant in stroke. J Cereb Blood Flow Metab 20, 631 - 652 (2000)

2 Mendelsohn ME and Karas RH: The protective effects of estrogen on the cardiovascular system. N Engl J Med 340, $1801-$ 1811 (1999)

3 Shughrue PJ, Scrimo PJ and Merchenthaler I: Evidence for the colocalization of estrogen receptor-beta mRNA and estrogen receptor-alpha immunoreactivity in neurons of the rat forebrain. Endocrinology 139, 5267 - 5270 (1998)

4 Shughrue PJ, Lane MV and Merchenthaler I: Biologically active estrogen receptor-beta: Evidence from in vivo autoradiographic studies with estrogen receptor alpha-knockout mice. Endocrinology 140, 2613 - 2620 (1999)

5 Singh M, Setalo GJ, Guan X, Frail DE and Toran-Allerand CD: Estrogen-induced activation of the mitogen-activated protein kinase cascade in the cerebral cortex of estrogen receptor-alpha knock-out mice. J Neurosci 20, 1694 - 1700 (2000)

6 Reynolds SR and Foster FI: Peripheral vascular action of estro- 

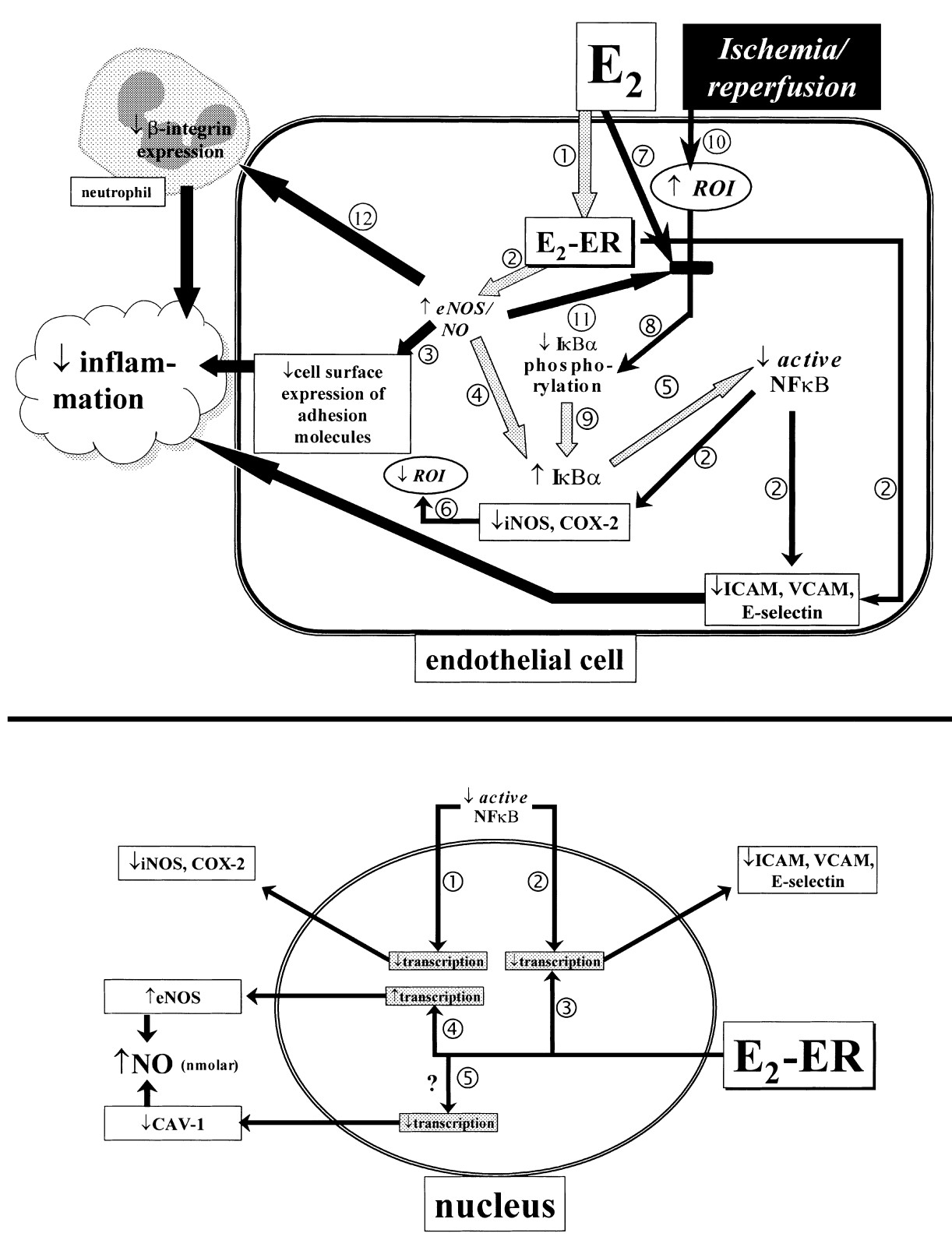

Fig. 8. Multiple pathways may participate in mediating the reported capability of $E_{2}$ to suppress leukocyte-endothelial interactions and limit tissue inflammation. Upper panel: $E_{2}$ may act via its receptor (ER, pathway 1), forming a complex $\left(\mathrm{E}_{2}-\mathrm{ER}\right)$ that interacts with the transcriptional machinery in the nucleus (pathway 2 and lower panel), leading to increased expression and activity of eNOS and reduced expression of adhesion molecules (e.g., ICAM, VCAM and E-selectin [see ref. 175]). $\mathrm{E}_{2}$ may also behave as an antioxidant (176) (pathway 7), diminishing the impact of the increase in reactive oxygen intermediates (ROI) associated with pathologic conditions like ischemia and reperfusion (pathway 10). Limiting increases in ROI levels will act to limit phosphorylation of the NF $\kappa \mathrm{B}$ inhibitory protein, I $\kappa \mathrm{B}-\alpha$ [pathway 8 (173)], and its subsequent degradation, resulting in increased $\mathrm{I} \kappa \mathrm{B}-\alpha$ levels (pathway 9). In turn, the higher $\mathrm{I} \kappa \mathrm{B}-\alpha$ levels will diminish the amount of active NF $\kappa \mathrm{B}$ that is present (pathway 5). Lesser $\mathrm{NF} \kappa \mathrm{B}$ abundance will limit the cell's capacity to increase the synthesis of adhesion molecules, iNOS or COX-2 (pathway 2 and lower panel). Increased generation of eNOS-derived NO has been linked to prevention of mobilization of endothelial adhesion molecules to the cell surface [pathway 3 (155)], increased de novo synthesis of I $\kappa \mathrm{B}-\alpha$ [pathway 4 (170)], antioxidant actions (pathway 11) and diminished $\beta$-integrin expression [pathway 12 (169)]. The ability to prevent upregulation of iNOS and COX-2 will act to minimize ROI-related actions (pathway 6), which could also contribute to increased I $\kappa \mathrm{B}-\alpha$ activity. Lower panel: This panel depicts the possible transcriptional mechanisms influenced by $E_{2}$-ER actions within the nucleus, as well the transcriptional effects of a diminished $\mathrm{NF} \kappa \mathrm{B}$ activity. A reduction in $\mathrm{NF} \kappa \mathrm{B}$ activity is likely to limit or prevent upregulation of iNOS, COX-2, or adhesion molecules [pathways 1 and $2(149,188)]$. Estrogen, via the complex formed with its receptor, has also been associated with reduced transcription of adhesion molecules [pathway $3(173,174)]$. The $\mathrm{E}_{2}$-ER complex has been linked to enhanced eNOS transcription (pathway 4). Recent findings have suggested an $\mathrm{E}_{2}$-associated reduction in CAV-1 expression [pathway 5 (80)], although it is not known whether that mechanism involves an $E_{2}$-ER interaction with the CAV-1 gene. The combination of increased eNOS and diminished CAV-1 expression will greatly enhance eNOS-derived NO generation. 
gen, observed in the ear of the rabbit. J Pharmacol Exp Ther 68, $173-184(1940)$

7 Stefano GB, Prevot V, Beauvillain JC, Cadet P, Fimiani C, Welters I, Fricchione GL, Breton C, Lassalle P, Salzet M and Bilfinger TV: Cell-surface estrogen receptors mediate calcium-dependent nitric oxide release in human endothelia. Circulation 101, 1594 - 1597 (2000)

8 Dubey RK, Gillespie DG, Mi Z, Rosselli M, Keller PJ and Jackson EK: Estradiol inhibits smooth muscle cell growth in part by activating the cAMP-adenosine pathway. Hypertension 35, $262-266(2000)$

9 Farhat MY, Abiyounes S, Dingaan B, Vargas R and Ramwell PW: Estradiol increases cyclic adenosine monophosphate in rat pulmonary vascular smooth muscle cells by a nongenomic mechanism. J Pharmacol Exp Ther 276, 652 - 657 (1996)

10 Wellman GC, Bonev AD, Nelson MT and Brayden JE: Gender differences in coronary artery diameter involve estrogen, nitric oxide, and $\mathrm{Ca}^{2+}$-dependent $\mathrm{K}^{+}$channels. Circ Res 79, $1024-$ 1030 (1996)

11 Valverde MA, Rojas P, Amigo J, Cosmelli D, Orio P, Bahamonde MI, Mann GE, Vergara C and Latorre R: Acute activation of Maxi-K channels (hSlo) by estradiol binding to the beta subunit. Science 285, 1929 - 1931 (1999)

12 Gonzales RJ and Kanagy NL: Endothelium-independent relaxation of vascular smooth muscle by 17 beta-estradiol. J Cardiovasc Pharmacol Ther 4, 227 - 234 (1999)

13 Baldi E, Luconi M, Muratori M and Forti G: A novel functional estrogen receptor on human sperm membrane interferes with progesterone effects. Mol Cell Endocrinol 161, 31 - 35 (2000)

14 Kim HP, Lee JY, Jeong JK, Bae SW, Lee HK and Jo I: Nongenomic stimulation of nitric oxide release by estrogen is mediated by estrogen receptor alpha localized in caveolae. Biochem Biophys Res Commun 263, 257 - 262 (1999)

15 Razandi M, Pedram A, Greene GL and Levin ER: Cell membrane and nuclear estrogen receptors (ERs) originate from a single transcript: studies of ER $\alpha$ and ER $\beta$ expressed in Chinese hamster ovary cells. Mol Endocrinol 13, $307-319$ (1999)

16 Huang A, Sun D, Koller A and Kaley G: 17 beta-Estradiol restores endothelial nitric oxide release to shear stress in arterioles of male hypertensive rats. Circulation 101, $94-100$ (2000)

17 Caulinglaser T, Garciacardena G, Sarrel P, Sessa WC and Bender JR: 17 beta-Estradiol regulation of human endothelial cell basal nitric oxide release, independent of cytosolic $\mathrm{Ca}^{2+}$ mobilization. Circ Res 81, 885 - 892 (1997)

18 Russell KS, Haynes MP, Caulin-Glaser T, Rosneck J, Sessa WC and Bender JR: Estrogen stimulates heat shock protein 90 binding to endothelial nitric oxide synthase in human vascular endothelial cells. Effects on calcium sensitivity and NO release. J Biol Chem 275, 5026 - 5030 (2000)

19 Goetz RM, Thatte HS, Prabhakar P, Cho MR, Michel T and Golan DE: Estradiol induces the calcium-dependent translocation of endothelial nitric oxide synthase. Proc Natl Acad Sci USA 96, 2788 - 2793 (1999)

20 leTran Y, Fung A and Forster C: Role of gender and vascular endothelium in rat aorta response to 17 beta-estradiol. Can J Physiol Pharmacol 75, 1393 - 1397 (1997)

21 Vacca G, Battaglia A, Grossini E, Mary DA, Molinari C and Surico N: The effect of 17 beta-oestradiol on regional blood flow in anaesthetized pigs. J Physiol (Lond) 514, 875 - 884 (1999)

22 Nechmad A, Merin G, Schwalb H, Shimon DV, Borman JB,
Milgalter $\mathrm{E}$ and Mosseri M: Estrogen induces nitric oxidemediated vasodilation of human mammary arteries in vitro. Nitric Oxide 2, 460 - 466 (1998)

23 Bell DR, Rensberger HJ, Koritnik DR and Koshy A: Estrogen pretreatment directly potentiates endothelium-dependent vasorelaxation of porcine coronary arteries. Am J Physiol 268, H377 - H383 (1995)

24 Naderali EK, Walker AB, Doyle P and Williams G: Comparable vasorelaxant effects of 17 alpha- and 17 beta-oestradiol on rat mesenteric resistance arteries: an action independent of the oestrogen receptor. Clin Sci (Colch) 97, 649 - 655 (1999)

25 Sudhir K, Chou TM, Mullen WL, Hausmann D, Collins P, Yock PG and Chatterjee K: Mechanisms of estrogen-induced vasodilation: in vivo studies in canine coronary conductance and resistance arteries. J Am Coll Cardiol 26, 807 - 814 (1995)

26 Mugge A, Riedel M, Barton M, Kuhn M and Lichtlen PR: Endothelium independent relaxation of human coronary arteries by 17 beta-oestradiol in vitro. Cardiovasc Res 27, $1939-1942$ (1993)

27 Shaw L, Taggart MJ and Austin C: Mechanisms of 17 betaoestradiol induced vasodilatation in isolated pressurized rat small arteries. Br J Pharmacol 129, 555 - 565 (2000)

28 Guetta V, Quyyumi AA, Prasad A, Panza JA, Waclawiw M and Cannon RO: The role of nitric oxide in coronary vascular effects of estrogen in postmenopausal women. Circulation 96, $2795-$ 2801 (1997)

29 Hugel S, Neubauer S, Lie SZ, Ernst R, Horn M, Schmidt HH, Allolio B and Reincke M: Multiple mechanisms are involved in the acute vasodilatory effect of 17 beta-estradiol in the isolated perfused rat heart. J Cardiovasc Pharmacol 33, 852 - 858 (1999)

30 Seeger H, Mueck AO and Lippert TH: Effect of estradiol metabolites on prostacyclin synthesis in human endothelial cell cultures. Life Sci 65, L167 - L170 (1999)

31 Chang WC, Nakao J, Orimo H and Murota S: Stimulation of prostacyclin biosynthetic activity by estradiol in rat aortic smooth muscle cells in culture. Biochim Biophys Acta 619, 107 - 118 (1980)

32 Murphy JG and Khalil RA: Decreased $\left[\mathrm{Ca}^{2+}\right]_{i}$ during inhibition of coronary smooth muscle contraction by 17 beta-estradiol, progesterone, and testosterone. J Pharmacol Exp Ther 291, 44 52 (1999)

33 Kitazawa T, Hamada E, Kitazawa K and Gaznabi AK: Nongenomic mechanism of 17 beta-oestradiol-induced inhibition of contraction in mammalian vascular smooth muscle. J Physiol (Lond) 499, 497 - 511 (1997)

34 White RE, Darkow DJ and Lang JLF: Estrogen relaxes coronary arteries by opening BKCa channels through a cGMP-dependent mechanism. Circ Res 77, 936 - 942 (1995)

35 Nakajima T, Kitazawa T, Hamada E, Hazama H, Omata M and Kurachi Y: 17 Beta-estradiol inhibits the voltage-dependent 1type $\mathrm{Ca}^{2+}$ currents in aortic smooth muscle cells. Eur J Pharmacol 294, $625-635$ (1995)

36 Zuckerman S and Son M: Estrogen-induced pial arteriolar dilation is prostanoid-associated in the newborn. FASEB J 11, A21 (1997)

37 Futo J, Shay J, Block S, Holt J, Beach M and Moss J: Estrogen and progesterone withdrawal increases cerebral vasoreactivity to serotonin in rabbit basilar artery. Life Sci 50, $1165-1172$ (1992)

38 Ghanam K, Javellaud J, Ea-Kim L and Oudart N: Effects of 
treatment with 17 beta-estradiol on the hypercholesterolemic rabbit middle cerebral artery. Maturitas 34, $249-260$ (2000)

39 Ogata R, Inoue Y, Nakano H, Ito Y and Kitamura K: Oestradiolinduced relaxation of rabbit basilar artery by inhibition of voltage-dependent $\mathrm{Ca}$ channels through GTP-binding protein. Br J Pharmacol 117, 351 - 359 (1996)

40 Littleton-Kearney MT, Agnew DM, Traystman RJ and Hurn PD: Effects of estrogen on cerebral blood flow and pial microvasculature in rabbit. Am J Physiol 279, H1208 - H1214 (2000)

41 Hsueh AJ and Billig H: Ovarian hormone synthesis and mechanism of action. In Endocrinology, 3rd edition, Edited by Degroot LS, pp 2019 - 2030, WB Saunders Co, Philadelphia (1995)

42 Södergård R, Bäckström $\mathrm{T}$, Shanbhag $\mathrm{V}$ and Carstensen $\mathrm{H}$ : Calculation of free and bound fractions of testosterone and estradiol-17 beta to human plasma proteins at body temperature. J Steroid Biochem 16, $801-810$ (1982)

43 Toniolo P, Koenig KL, Pasternack BS, Banerjee S, Rosenberg C, Shore RE, Strax P and Levitz M: Reliability of measurements of total, protein-bound, and unbound estradiol in serum. Cancer Epidemiol Biomarkers Prev 3, 47 - 50 (1994)

44 Kuiper GM, Shughrue PJ, Merchenthaler I and Gustafsson JA: The estrogen receptor beta subtype: a novel mediator of estrogen action in neuroendocrine systems. Front Neuroendocrinol 19, $253-286$ (1998)

45 Namba H and Sokoloff L: Acute administration of high doses of estrogen increases glucose utilization throughout brain. Brain Res 291, 391 - 394 (1984)

46 Tauboll E, Lindstrom S and Gjerstad L: Acute effects of 17 betaestradiol on brain excitability studied in vitro and in vivo. Epilepsy Res 18, 107 - 117 (1994)

47 Mize AL and Alper RH: Acute and long-term effects of $17 \beta$ estradiol on $\mathrm{G}(\mathrm{i} / \mathrm{o})$ coupled neurotransmitter receptor function in the female rat brain as assessed by agonist-stimulated $\left[{ }^{35} \mathrm{~S}\right] \mathrm{GTP} \gamma \mathrm{S}$ binding. Brain Res 859, $326-333$ (2000)

48 Kelly MJ, Lagrange AH, Wagner EJ and Ronnekleiv OK: Rapid effects of estrogen to modulate $\mathrm{G}$ protein-coupled receptors via activation of protein kinase $A$ and protein kinase $C$ pathways. Steroids 64, $64-75$ (1999)

49 Lagrange AH, Ronnekleiv OK and Kelly MJ: Modulation of $G$ protein-coupled receptors by an estrogen receptor that activates protein kinase A. Mol Pharmacol 51, 605 - 612 (1997)

50 Phillis JW and O'Regan MH: Effects of estradiol on cerebral cortical neurons and their responses to adenosine. Brain Res Bull 20, 151 - 155 (1988)

$51 \mathrm{Gu}$ Q and Moss RL: Novel mechanism for non-genomic action of 17 beta-oestradiol on kainate-induced currents in isolated rat CA1 hippocampal neurones. J Physiol (Lond) 506, 745 - 754 (1998)

52 Gu Q, Korach KS and Moss RL: Rapid action of 17 beta-estradiol on kainate-induced currents in hippocampal neurons lacking intracellular estrogen receptors. Endocrinology 140, 660-666 (1999)

53 Pasqualini C, Olivier V, Guibert B, Frain O and Leviel V: Acute stimulatory effect of estradiol on striatal dopamine synthesis. J Neurochem 65, 1651 - 1657 (1995)

$54 \mathrm{Gu} \mathrm{Q}$ and Moss RL: 17 Beta-estradiol potentiates kainateinduced currents via activation of the cAMP cascade. J Neurosci 16, 3620 - 3629 (1996)

55 Kauser K and Rubanyi GM: Gender difference in bioassayable endothelium-derived nitric oxide from isolated rat aortae. Am J
Physiol 267, H2311 - H2317 (1994)

56 Hayashi T, Fukuto JM, Ignarro LJ and Chaudhuri G: Basal release of nitric oxide from aortic rings is greater in female rabbits than in male rabbits: implications for atherosclerosis. Proc Natl Acad Sci USA 89, 11259 - 11263 (1992)

57 Huang A, Sun D, Koller A and Kaley G: Gender difference in myogenic tone of rat arterioles is due to estrogen-induced, enhanced release of NO. Am J Physiol 272, H1804-H1809 (1997)

58 Huang A, Sun D, Koller A and Kaley G: Gender difference in flow-induced dilation and regulation of shear stress: role of estrogen and nitric oxide. Am J Physiol 275, R1571 - R1577 (1998)

59 Barber DA and Miller VM: Gender differences in endotheliumdependent relaxations do not involve NO in porcine coronary arteries. Am J Physiol 273, H2325 - H2332 (1997)

60 Rubanyi GM, Freay AD, Kauser K, Sukovich D, Burton G, Lubahn DB, Couse JF, Curtis SW and Korach KS: Vascular estrogen receptors and endothelium-derived nitric oxide production in the mouse aorta - gender difference and effect of estrogen receptor gene disruption. J Clin Invest 99, 2429 - 2437 (1997)

61 Meredith IT, Currie KE, Anderson TJ, Roddy MA, Ganz P and Creager MA: Postischemic vasodilation in human forearm is dependent on endothelium-derived nitric oxide. Am J Physiol 270, H1435 - H1440 (1996)

62 Kawano H, Motoyama T, Kugiyama K, Hirashima O, Ohgushi M, Fujii H, Ogawa $\mathrm{H}$ and Yasue $\mathrm{H}$ : Gender difference in improvement of endothelium-dependent vasodilation after estrogen supplementation. J Am Coll Cardiol 30, 914-919 (1997)

63 Lim SC, Caballero AE, Arora S, Smakowski P, Bashoff EM, Brown FM, LoGerfo FW, Horton ES and Veves A: The effect of hormonal replacement therapy on the vascular reactivity and endothelial function of healthy individuals and individuals with type 2 diabetes. J Clin Endocrinol Metab 84, 4159 - 4164 (1999)

64 Perregaux D, Chaudhuri A, Mohanty P, Bukhari L, Wilson MF, Sung BH and Dandona P: Effect of gender differences and estrogen replacement therapy on vascular reactivity. Metabolism 48, 227 - 232 (1999)

65 New G, Duffy SJ, Harper RW and Meredith IT: Estrogen improves acetylcholine-induced but not metabolic vasodilation in biological males. Am J Physiol 277, H2341 - H2347 (1999)

66 New G, Duffy SJ, Harper RW and Meredith IT: Long-term oestrogen therapy is associated with improved endotheliumdependent vasodilation in the forearm resistance circulation of biological males. Clin Exp Pharmacol Physiol 27, 25 - 33 (2000)

67 Weiner CP, Martinez E, Chestnut DH and Ghodsi A: Effect of pregnancy on uterine and carotid artery response to norepinephrine, epinephrine, and phenylephrine in vessels with documented functional endothelium. Am J Obstet Gynecol 161, 1605 - 1610 (1989)

68 Saito S, Foegh ML, Ramwell PW and Koyanagi H: Estradiol effects on nitric oxide synthase expression in the rat aorta allograft. Transplant Proc 31, 2025 - 2027 (1999)

69 Weiner CP, Lizasoain I, Baylis SA, Knowles RG, Charles IG and Moncada S: Induction of calcium-dependent nitric oxide synthases by sex hormones. Proc Natl Acad Sci USA 91, 5212 5216 (1994)

70 Hayashi T, Yamada K, Esaki T, Kuzuya M, Satake S, Ishikawa $\mathrm{T}$, Hidaka $\mathrm{H}$ and Iguchi $\mathrm{A}$ : Estrogen increases endothelial nitric 
oxide by a receptor-mediated system. Biochem Biophys Res Commun 214, 847 - 855 (1995)

71 Kauser K and Rubanyi GM: Potential cellular signaling mechanisms mediating upregulation of endothelial nitric oxide production by estrogen. J Vasc Res 34, 229 - 236 (1997)

72 Hishikawa K, Nakaki T, Marumo T, Suzuki H, Kato R and Saruta T: Up-regulation of nitric oxide synthase by estradiol in human aortic endothelial cells. FEBS Lett 360, 291 - 293 (1995)

73 Geary GG, Krause DN and Duckles SP: Estrogen reduces myogenic tone through a nitric oxide-dependent mechanism in rat cerebral arteries. Am J Physiol 275, H292 - H300 (1998)

74 Skarsgard P, Vanbreemen C and Laher I: Estrogen regulates myogenic tone in pressurized cerebral arteries by enhanced basal release of nitric oxide. Am J Physiol 273, H2248 - H2256 (1997)

75 Palmon SC, Williams MJ, LittletonKearney MT, Traystman RJ, Koskkosicka D and Hurn PD: Estrogen increases cGMP in selected brain regions and in cerebral microvessels. J Cereb Blood Flow Metab 18, 1248 - 1252 (1998)

76 Alkayed NJ, Harukuni I, Kimes AS, London ED, Traystman RJ and Hurn PD: Gender-linked brain injury in experimental stroke. Stroke 29, 159 - 165 (1998)

77 Holschneider DP and Scremin OU: Effects of ovariectomy on cerebral blood flow of rats. Neuroendocrinology 67, 260-268 (1998)

78 Wang Q, Santizo R, Baughman VL and Pelligrino DA: Estrogen provides neuroprotection in transient forebrain ischemia through perfusion-independent mechanisms in rats. Stroke 30, 630 - 637 (1999)

79 Penotti M, Sironi L, Miglierina L, Farina M, Barletta L, Gabrielli L and Vignali M: The effect of tamoxifen and transdermal 17 beta-estradiol on cerebral arterial vessels: a randomized controlled study. Am J Obstet Gynecol 178, $801-805$ (1998)

80 Pelligrino DA, Ye S, Tan F, Santizo RA, Feinstein DL and Wang Q: Nitric-oxide-dependent pial arteriolar dilation in the female rat: effects of chronic estrogen depletion and repletion. Biochem Biophys Res Commun 269, 165 - 171 (2000)

81 Pelligrino DA and Santizo RA: Estrogen effects on endothelial nitric oxide synthase (eNOS)-dependent vasodilation in different brain regions. FASEB J 14, A151 (2000)

82 McNeill AM, Kim N, Duckles SP and Krause DN: Chronic estrogen treatment increases levels of endothelial nitric oxide synthase protein in rat cerebral microvessels. Stroke 30, $2186-$ 2190 (1999)

83 Shughrue PJ, Lane MV and Merchenthaler I: Regulation of progesterone receptor messenger ribonucleic acid in the rat medial preoptic nucleus by estrogenic and antiestrogenic compounds: an in situ hybridization study. Endocrinology 138, 5476 - 5484 (1997)

84 Shughrue PJ and Merchenthaler I: Estrogen is more than just a "sex hormone": novel sites for estrogen action in the hippocampus and cerebral cortex. Front Neuroendocrinol 21, $95-101$ (2000)

85 Dubal DB, Shughrue PJ, Wilson ME, Merchenthaler I and Wise PM: Estradiol modulates bcl-2 in cerebral ischemia: a potential role for estrogen receptors. J Neurosci 19, 6385 - 6393 (1999)

86 Asaithambi A, Mukherjee S and Thakur MK: Expression of 112-kda estrogen receptor in mouse brain cortex and its autoregulation with age. Biochem Biophys Res Commun 231, 683 -
685 (1997)

87 Feron O, Saldana F, Michel JB and Michel T: The endothelial nitric-oxide synthase-caveolin regulatory cycle. J Biol Chem 273, $3125-3128$ (1998)

88 Garciacardena G, Martasek P, Masters BS, Skidd PM, Couet J, Li SW, Lisanti MP and Sessa WC: Dissecting the interaction between nitric oxide synthase (NOS) and caveolin - functional significance of the NOS caveolin binding domain in vivo. J Biol Chem 272, 25437 - 25440 (1997)

89 Mcdonald KK, Zharikov S, Block ER and Kilberg MS: A caveolar complex between the cationic amino acid transporter 1 and endothelial nitric-oxide synthase may explain the "arginine paradox". J Biol Chem 272, 31213 - 31216 (1997)

90 Fujimoto T, Miyawaki A and Mikoshiba K: Inositol 1,4,5trisphosphate receptor-like protein in plasmalemmal caveolae is linked to actin filaments. J Cell Sci 108, 7 - 15 (1995)

91 Feron O, Smith TW, Michel T and Kelly RA: Dynamic targeting of the agonist-stimulated $\mathrm{m} 2$ muscarinic acetylcholine receptor to caveolae in cardiac myocytes. J Biol Chem 272, $17744-$ 17748 (1997)

92 Feron O, Dessy C, Moniotte S, Desager JP and Balligand JL: Hypercholesterolemia decreases nitric oxide production by promoting the interaction of caveolin and endothelial nitric oxide synthase. J Clin Invest 103, 897 - 905 (1999)

93 Ye S, Santizo RA and Pelligrino DA: Estrogen effects on endothelial nitric oxide synthase (eNOS) and caveolin-1 (CAV-1) expression in different brain regions. FASEB J 14, A151 (2000)

94 Bist A, Fielding PE and Fielding CJ: Two sterol regulatory element-like sequences mediate up-regulation of caveolin gene transcription in response to low density lipoprotein free cholesterol. Proc Natl Acad Sci USA 94, 10693 - 10698 (1997)

95 Fielding CJ, Bist A and Fielding PE: Caveolin mRNA levels are up-regulated by free cholesterol and down-regulated by oxysterols in fibroblast monolayers. Proc Natl Acad Sci USA 94, 3753 - 3758 (1997)

96 Liu D and Bachmann KA: An investigation of the relationship between estrogen, estrogen metabolites and blood cholesterol levels in ovariectomized rats. J Pharmacol Exp Ther 286, 561 568 (1998)

97 Segnitz B and Gehring U: The function of steroid hormone receptors is inhibited by the hsp90-specific compound geldanamycin. J Biol Chem 272, 18694 - 18701 (1997)

98 Geary GG, Korach KS, Krause DN and Duckles SP: Estrogen receptor $\alpha$-deficient mice lack estrogen effect on nitric oxide synthase in cerebral arteries. Soc Neurosci Abst 26, 1731 (2000)

99 Viswanathan M, Rivera O and Short BL: Heat shock protein 90 is involved in pulsatile flow-induced dilation of rat middle cerebral artery. J Vasc Res 36, 524 - 527 (1999)

100 Coffer PJ, Jin J and Woodgett JR: Protein kinase B (c-Akt): a multifunctional mediator of phosphatidylinositol 3-kinase activation. Biochem J 335, 1 - 13 (1998)

101 Honda K, Sawada H, Kihara T, Urushitani M, Nakamizo T, Akaike A and Shimohama S: Phosphatidylinositol 3-kinase mediates neuroprotection by estrogen in cultured cortical neurons. J Neurosci Res 60, 321 - 327 (2000)

102 Michell BJ, Griffiths JE, Mitchelhill KI, Rodriguez-Crespo I, Tiganis T, Bozinovski S, de Montellano PR, Kemp BE and Pęarson RB: The Akt kinase signals directly to endothelial nitric oxide synthase. Curr Biol 9, 845 - 848 (1999)

103 Mcmillan PJ, Singer CA and Dorsa DM: The effects of ovariec- 
tomy and estrogen replacement on trka and choline acetyltransferase mRNA expression in the basal forebrain of the adult female sprague-dawley rat. J Neurosci 16, 1860 - 1865 (1996)

104 Gibbs RB: Treatment with estrogen and progesterone affects relative levels of brain-derived neurotrophic factor mRNA and protein in different regions of the adult rat brain. Brain Res 844, 20 - 27 (1999)

105 Singh M, Meyer EM and Simpkins JW: The effect of ovariectomy and estradiol replacement on brain-derived neurotrophic factor messenger ribonucleic acid expression in cortical and hippocampal brain regions of female sprague-dawley rats. Endocrinology 136, 2320 - 2324 (1995)

106 Toran-Allerand CD, Singh M and Setalo G: Novel mechanisms of estrogen action in the brain: New players in an old story. Front Neuroendocrinol 20, 97 - 121 (1999)

107 Habermehl DA, Janowiak MA, Vagnoni KE, Bird IM and Magness RR: Endothelial vasodilator production by uterine and systemic arteries. IV. Cyclooxygenase isoform expression during the ovarian cycle and pregnancy in sheep. Biol Reprod 62, $781-788(2000)$

108 Mikkola T, Viinikka L and Ylikorkala O: Administration of transdermal estrogen without progestin increases the capacity of plasma and serum to stimulate prostacyclin production in human vascular endothelial cells. Fertil Steril 73, 72 - 74 (2000)

109 Jun SS, Chen Z, Pace MC and Shaul PW: Estrogen upregulates cyclooxygenase-1 gene expression in ovine fetal pulmonary artery endothelium. J Clin Invest 102, 176 - 183 (1998)

110 Bolego C, Cignarella A, Ruzza R, Zaarour C, Messi E, Zanisi M and Puglisi L: Differential effects of low- and high-dose estrogen treatments on vascular responses in female rats. Life Sci 60, $2291-2302$ (1997)

$111 \mathrm{Wu}$ WX, Ma XH and Nathanielsz PW: Changes in prostacyclin synthase in pregnant sheep myometrium, endometrium, and placenta at spontaneous term labor and regulation by estradiol and progesterone. Am J Obstet Gynecol 180, 744 - 749 (1999)

112 Case J and Davison CA: Estrogen alters relative contributions of nitric oxide and cyclooxygenase products to endotheliumdependent vasodilation. J Pharmacol Exp Ther 291, 524 - 530 (1999)

113 Davidge ST and Zhang YL: Estrogen replacement suppresses a prostaglandin $\mathrm{H}$ synthase-dependent vasoconstrictor in rat mesenteric arteries. Circ Res 83, 388 - 395 (1998)

114 Rage F, Lee BJ, Ma YJ and Ojeda SR: Estradiol enhances prostaglandin E2 receptor gene expression in luteinizing hormone-releasing hormone (LHRH) neurons and facilitates the LHRH response to PGE2 by activating a glia-to-neuron signaling pathway. J Neurosci 17, 9145 - 9156 (1997)

115 Butti G, Gaetani P, Chiabrando C, Assietti R, Zibera C, Castelli MG, Gibelli N, Silvani V, Robustelli della Cuna G and Paoletti P: A study on the biological behavior of human brain tumors. Part II: steroid receptors and arachidonic acid metabolism. J Neurooncol 10, 241 - 246 (1991)

116 Geary GG, Krause DN and Duckles SP: Estrogen reduces mouse cerebral artery tone through endothelial NOS- and cyclooxygenase-dependent mechanisms. Am J Physiol 279, H511 - 519 (2000)

117 Gerber RT, Anwar MA and Poston L: Enhanced acetylcholine induced relaxation in small mesenteric arteries from pregnant rats: an important role for endothelium-derived hyperpolarizing factor (EDHF). Br J Pharmacol 125, 455 - 460 (1998)
118 Bobadilla RA, Henkel CC, Henkel EC, Escalante B and Hong E: Possible involvement of endothelium-derived hyperpolarizing factor in vascular responses of abdominal aorta from pregnant rats. Hypertension 30, 596 - 602 (1997)

119 Golding EM, Kepler HD, Shine HD and Bryan RM: Endothelium derived hyperpolarizing factor is downregulated in the cerebrovasculature of female rats. Soc Neurosci Abst 26, 1731 (2000)

120 Bhardwaj A, Northington FJ, Carhuapoma JR, Falck JR, Harder DR, Traystman RJ and Koehler RC: P-450 epoxygenase and NO synthase inhibitors reduce cerebral blood flow response to $N$-methyl-D-aspartate. Am J Physiol 279, H1616 - H1624 (2000)

121 Harder DR, Alkayed NJ, Lange AR, Gebremedhin D and Roman RJ: Functional hyperemia in the brain: hypothesis for astrocytederived vasodilator metabolites. Stroke 29, 229 - 234 (1998)

122 Weeks AD, Massmann AG, Monaghan JM, Crowther D, Duffy SR, Walker JJ and Figueroa JP: Decreasing estrogen in nonpregnant women lowers uterine myometrial type I nitric oxide synthase protein expression. Am J Obstet Gynecol 181, $25-30$ (1999)

123 Zhang J, Massmann GA, Mirabile CP and Figueroa JP: Nonpregnant sheep uterine type I and type III nitric oxide synthase expression is differentially regulated by estrogen. Biol Reprod 60, 1198 - 1203 (1999)

124 Berman JR, Mccarthy MM and Kyprianou N: Effect of estrogen withdrawal on nitric oxide synthase expression and apoptosis in the rat vagina. Urology 51, $650-656$ (1998)

125 Hayashi T, Ishikawa T, Yamada K, Kuzuya M, Naito M, Hidaka $\mathrm{H}$ and Iguchi A: Biphasic effect of estrogen on neuronal constitutive nitric oxide synthase via $\mathrm{Ca}^{2+}$-calmodulin dependent mechanism. Biochem Biophys Res Commun 203, 1013 - 1019 (1994)

126 Okamura H, Yokosuka M, McEwen BS and Hayashi S: Colocalization of NADPH-diaphorase and estrogen receptor immunoreactivity in the rat ventromedial hypothalamic nucleus: stimulatory effect of estrogen on NADPH-diaphorase activity. Endocrinology 135, 1705 - 1708 (1994)

127 Rachman IM, Unnerstall JR, Pfaff DW and Cohen RS: Regulation of neuronal nitric oxide synthase mRNA in lordosis-relevant neurons of the ventromedial hypothalamus following short-term estrogen treatment. Mol Brain Res 59, 105 - 108 (1998)

128 Lizasoain I, Weiner CP, Knowles RG and Moncada S: The ontogeny of cerebral and cerebellar nitric oxide synthase in the guinea pig and rat. Pediatr Res 39, 779 - 783 (1996)

129 Pelligrino DA, Santizo R, Baughman VL and Wang Q: Cerebral vasodilating capacity during transient forebrain ischemia: the effects of chronic estrogen depletion and repletion and the role of neuronal nitric oxide synthase. Neuroreport 9, $3285-$ 3291 (1998)

130 Qian X, Jin L and Lloyd RV: Estrogen downregulates neuronal nitric oxide synthase in rat anterior pituitary cells and GH3 tumors. Endocrine 11, 123 - 130 (1999)

131 Gibbs RB and Aggarwal P: Estrogen and basal forebrain cholinergic neurons: implications for brain aging and Alzheimer's disease-related cognitive decline. Horm Behav 34, 98-111 (1998)

132 Gibbs RB: Fluctuations in relative levels of choline acetyltransferase mRNA in different regions of the rat basal forebrain across the estrous cycle: effects of estrogen and progesterone. J Neurosci 16, 1049 - 1055 (1996) 
133 Gibbs RB and Pfaff DW: Effects of estrogen and fimbria/fornix transection on p75NGFR and ChAT expression in the medial septum and diagonal band of Broca. Exp Neurol 116, 23-39 (1992)

134 Mufson EJ, Cai WJ, Jaffar S, Chen E, Stebbins G, Sendera T and Kordower JH: Estrogen receptor immunoreactivity within subregions of the rat forebrain: neuronal distribution and association with perikarya containing choline acetyltransferase. Brain Res 849, 253 - 274 (1999)

135 Packard MG and Teather LA: Intra-hippocampal estradiol infusion enhances memory in ovariectomized rats. Neuroreport $\mathbf{8}$, 3009 - 3013 (1997)

136 Fader AJ, Johnson PM and Dohanich GP: Estrogen improves working but not reference memory and prevents amnestic effects of scopolamine on a radial-arm maze. Pharmacol Biochem Behav 62, 711 - 717 (1999)

137 Dohanich GP, Witcher JA, Weaver DR and Clemens LG: Alteration of muscarinic binding in specific brain areas following estrogen treatment. Brain Res 241, 347 - 350 (1982)

138 Olsen KL, Edwards E, Schechter N and Whalen RE: Muscarinic receptors in preoptic area and hypothalamus: effects of cyclicity, sex and estrogen treatment. Brain Res 448, 223 - 229 (1988)

139 Woolley CS: Effects of estrogen in the CNS. Curr Opin Neurobiol 9, 349 - 354 (1999)

140 Calizo LH and Flanagan-Cato LM: Estrogen selectively regulates spine density within the dendritic arbor of rat ventromedial hypothalamic neurons. J Neurosci 20, 1589 - 1596 (2000)

141 Liu X, Passant U, Risberg J, Warkentin S and Brun A: Synapse density related to cerebral blood flow and symptomatology in frontal lobe degeneration and Alzheimer's disease. Dement Geriatr Cogn Disord 10, Suppl 1, 64 - 70 (1999)

142 Cyr M, Ghribi O and Di PT: Regional and selective effects of oestradiol and progesterone on NMDA and AMPA receptors in the rat brain. J Neuroendocrinol 12, $445-452$ (2000)

143 Lovick TA, Brown LA and Key BJ: Neurovascular relationships in hippocampal slices: physiological and anatomical studies of mechanisms underlying flow-metabolism coupling in intraparenchymal microvessels. Neuroscience 92, 47 - 60 (1999)

144 Weaver CE, Parkchung M, Gibbs TT and Farb DH: 17 Betaestradiol protects against NMDA-induced excitotoxicity by direct inhibition of NMDA receptors. Brain Res 761, 338 - 341 (1997)

145 Kritzer MF and Kohama SG: Ovarian hormones influence the morphology, distribution, and density of tyrosine hydroxylase immunoreactive axons in the dorsolateral prefrontal cortex of adult rhesus monkeys. J Comp Neurol 395, 1 - 17 (1998)

146 Quesada A and Etgen AM: Tyrosine kinase effects on adrenoceptor-stimulated cyclic AMP accumulation in preoptic area and hypothalamus of female rats: modulation by estradiol. Brain Res 861, 117 - 125 (2000)

147 Bryan RM, Eichler MY, Swafford MWG, Johnson TD, Suresh MS and Childres WF: Stimulation of alpha(2) adrenoceptors dilates the rat middle cerebral artery. Anesthesiology 85, $82-90$ (1996)

148 Garcia MV, Cabezas JA and Perez-Gonzalez MN: Effects of oestradiol, testosterone and medroxyprogesterone on subcellular fraction marker enzyme activities from rat liver and brain. Comp Biochem Physiol [B] 80, 347 - 354 (1985)

149 del Zoppo G, Ginis I, Hallenbeck JM, Iadecola C, Wang X and Feuerstein GZ: Inflammation and stroke: putative role for cytokines, adhesion molecules and iNOS in brain response to ischemia. Brain Pathol 10, 95 - 112 (2000)

150 Sharar SR, Winn RK and Harlan JM: The adhesion cascade and anti-adhesion therapy: an overview. Springer Semin Immunopathol 16, 359 - 378 (1995)

151 Yang J, Furie BC and Furie B: The biology of P-selectin glycoprotein ligand-1: its role as a selectin counterreceptor in leukocyte-endothelial and leukocyte-platelet interaction. Thromb Haemost 81, 1 - 7 (1999)

152 Cid MC, Kleinman HK, Grant DS, Schnaper HW, Fauci AS and Hoffman GS: Estradiol enhances leukocyte binding to tumor necrosis factor (TNF)-stimulated endothelial cells via an increase in TNF-induced adhesion molecules E-selectin, intercellular adhesion molecule type 1 , and vascular cell adhesion molecule type 1. J Clin Invest 93, 17 - 25 (1994)

153 Squadrito F, Altavilla D, Squadrito G, Campo GM, Arlotta M, Arcoraci V, Minutoli L, Serrano M, Saitta A and Caputi AP: 17 Beta-oestradiol reduces cardiac leukocyte accumulation in myocardial ischaemia reperfusion injury in rat. Eur $\mathrm{J}$ Pharmacol 335, 185 - 192 (1997)

154 Burns AR, Bowden RA, Abe Y, Walker DC, Simon SI, Entman ML and Smith CW: P-selectin mediates neutrophil adhesion to endothelial cell borders. J Leukoc Biol 65, 299 - 306 (1999)

155 Pernerstorfer T, Stohlawetz P, Kapiotis S, Eichler HG and Jilma B: Partial inhibition of nitric oxide synthase primes the stimulated pathway of vWF-secretion in man. Atherosclerosis 148, $43-47(2000)$

156 Kupatt C, Weber C, Wolf DA, Becker BF, Smith TW and Kelly RA: Nitric oxide attenuates reoxygenation-induced ICAM-1 expression in coronary microvascular endothelium: Role of NF kappa B. J Mol Cell Cardiol 29, 2599 - 2609 (1997)

157 Khan BV, Harrison DG, Olbrych MT, Alexander RW and Medford RM: Nitric oxide regulates vascular cell adhesion molecule 1 gene expression and redox-sensitive transcriptional events in human vascular endothelial cells. Proc Natl Acad Sci USA 93, 9114 - 9119 (1996)

158 Caulinglaser T, Watson CA, Pardi R and Bender JR: Effects of 17 beta-estradiol on cytokine-induced endothelial cell adhesion molecule expression. J Clin Invest 98, 36 - 42 (1996)

159 Simoncini T, Decaterina R and Genazzani AR: Selective estrogen receptor modulators: Different actions on vascular cell adhesion molecule-1 (VCAM-1) expression in human endothelial cells. J Clin Endocrinol Metab 84, 815 - 818 (1999)

160 Nathan L, Pervin S, Singh R, Rosenfeld M and Chaudhuri G: Estradiol inhibits leukocyte adhesion and transendothelial migration in rabbits in vivo-Possible mechanisms for gender differences in atherosclerosis. Circ Res 85, 377 - 385 (1999)

161 Koh KK, Bui MN, Mincemoyer R and Cannon RO: Effects of hormone therapy on inflammatory cell adhesion molecules in postmenopausal healthy women. Am J Cardiol 80, 1505 - 1507 (1997)

162 Armstead VE, Minchenko AG, Schuhl RA, Hayward R, Nossuli $\mathrm{TO}$ and Lefer AM: Regulation of P-selectin expression in human endothelial cells by nitric oxide. Am J Physiol Heart Circ Phy 42, H740 - H746 (1997)

163 Delyani JA, Murohara T, Nossuli TO and Lefer AM: Protection from myocardial reperfusion injury by acute administration of 17 beta-estradiol. J Mol Cell Cardiol 28, 1001 - 1008 (1996)

164 Lefer AM, Siegfried MR and Ma XL: Protection of ischemia reperfusion injury by sydnonimine $\mathrm{NO}$ donors via inhibition 
of neutrophil endothelium interaction. J Cardiovasc Pharmacol 22, S27 - S33 (1993)

165 Lefer AM and Lefer DJ: The role of nitric oxide and cell adhesion molecules on the microcirculation in ischaemiareperfusion. Cardiovasc Res 32, 743 - 751 (1996)

166 Niu XF, Smith CW and Kubes P: Intracellular oxidative stress induced by nitric oxide synthesis inhibition increases endothelial cell adhesion to neutrophils. Circ Res 74, 1133 - 1140 (1994)

167 Scalia R and Lefer AM: In vivo regulation of PECAM-1 activity during acute endothelial dysfunction in the rat mesenteric microvasculature. J Leukoc Biol 64, 163 - 169 (1998)

168 Lefer DJ, Jones SP, Girod WG, Baines A, Grisham MB, Cockrell AS, Huang PL and Scalia R: Leukocyte-endothelial cell interactions in nitric oxide synthase-deficient mice. Am J Physiol 276, H1943 - H1950 (1999)

169 Garcia-Duran M, deFrutos T, Diaz-Recasens J, Garcia-Galvez G, Jimenez A, Monton M, Farre J, Sanchez de Miguel L, Gonzalez-Fernandez F, Arriero MD, Rico L, Garcia R, Casado S and Lopez-Farre A: Estrogen stimulates neuronal nitric oxide synthase protein expression in human neutrophils. Circ Res 85, 1020 - 1026 (1999)

170 Spiecker M, Darius H, Kaboth K, Hubner F and Liao JK: Differential regulation of endothelial cell adhesion molecule expression by nitric oxide donors and antioxidants. J Leukoc Biol 63, 732 - 739 (1998)

171 Katsuyama K, Shichiri M, Marumo F and Hirata Y: NO inhibits cytokine-induced iNOS expression and NF-kappa B activation by interfering with phosphorylation and degradation of I kappa B-alpha. Arterioscler Thromb Vasc Biol 18, 1796 - 1802 (1998)

172 Nathan L, Pervin S, Singh R, Rosenfeld M and Chaudhuri G: Estradiol inhibits leukocyte adhesion and transendothelial migration in rabbits in vivo - Possible mechanisms for gender differences in atherosclerosis. Circ Res 85, 377 - 385 (1999)

173 Christman JW, Blackwell TS and Juurlink BH: Redox regulation of nuclear factor kappa B: therapeutic potential for attenuating inflammatory responses. Brain Pathol 10, 153 - 162 (2000)

174 Simoncini T, Decaterina R and Genazzani AR: Selective estrogen receptor modulators: Different actions on vascular cell adhesion molecule-1 (VCAM-1) expression in human endothelial cells. J Clin Endocrinol Metab 84, 815 - 818 (1999)

175 Simoncini T, Maffei S, Basta G, Barsacchi G, Genazzani AR, Liao JK and Decaterina R: Estrogens and glucocorticoids inhibit endothelial vascular cell adhesion molecule-1 expression by different transcriptional mechanisms. Circ Res 87, 19-25 (2000)

176 Green PS and Simpkins JW: Neuroprotective effects of estrogens: potential mechanisms of action. Int J Dev Neurosci 18, $347-358$ (2000)

177 Santizo R and Pelligrino DA: Estrogen reduces leukocyte adhesion in the cerebral circulation of female rats. J Cereb Blood Flow Metab 19, 1061 - 1065 (1999)

178 Santizo RA, Koenig HM and Pelligrino DA: Estrogen and leukocyte adhesion following transient forebrain ischemia in rats. Stroke 31, $2231-2235$ (2000)

179 Hudetz AG, Wood JD and Kampine JP: Nitric oxide synthase inhibitor augments post-ischemic leukocyte adhesion in the cerebral microcirculation in vivo. Neurol Res 21, 378-384 (1999)
180 Galea E, Issertial O, Seylaz J, Pelligrino DA and Pinard E: Chronic nitric oxide synthase inhibition does not induce cerebrovascular inflammation. Soc Neurosci Abst 26, 644 (2000)

181 Luvara G, Pueyo ME, Philippe M, Mandet C, Savoie F, Henrion D and Michel JB: Chronic blockade of NO synthase activity induces a proinflammatory phenotype in the arterial wall: prevention by angiotensin II antagonism. Arterioscler Thromb Vasc Biol 18, 1408 - 1416 (1998)

$182 \mathrm{Xu} \mathrm{R}$, Morales JA, Muniyappa R, Skafar DF, Ram JL and Sowers JR: Interleukin-1beta-induced nitric oxide production in rat aortic endothelial cells: Inhibition by estradiol in normal and high glucose cultures. Life Sci 64, 2451 - 2462 (1999)

183 Binko J, Murphy TV and Majewski H: 17 Beta-oestradiol enhances nitric oxide synthase activity in endothelium-denuded rat aorta. Clin Exp Pharmacol Physiol 25, 120 - 127 (1998)

184 Cho MM, Ziats NP, Pal D, Utian WH and Gorodeski GI: Estrogen modulates paracellular permeability of human endothelial cells by eNOS- and iNOS-related mechanisms. Am J Physiol Cell Physiol 45, C337 - C349 (1999)

185 Beckman JS and Koppenol WH: Nitric oxide, superoxide, and peroxynitrite: the good, the bad, and the ugly. Am J Physiol 271, C1424 - C1437 (1996)

186 Matsuoka Y, Okazaki M, Zhao H, Asai S, Ishikawa K and Kitamura Y: Phosphorylation of c-Jun and its localization with heme oxygenase- 1 and cyclooxygenase- 2 in CA1 pyramidal neurons after transient forebrain ischemia. J Cereb Blood Flow Metab 19, 1247 - 1255 (1999)

187 Morisset S, Patry C, Lora $\mathrm{M}$ and de Brum-Fernandes AJ: Regulation of cyclooxygenase-2 expression in bovine chondrocytes in culture by interleukin 1alpha, tumor necrosis factoralpha, glucocorticoids, and 17beta-estradiol. J Rheumatol 25, $1146-1153$ (1998)

188 Carrol JE, Hess DC, Howard EF and Hill WD: Is nuclear factorkappa $\mathrm{B}$ a good treatment target in brain ischemia/reperfusion injury? Neuroreport 11, R1 - R4 (2000)

189 Thomas T, Rhodin JA, Sutton ET, Bryant MW and Price JM: Estrogen protects peripheral and cerebral blood vessels from toxicity of Alzheimer peptide amyloid-beta and inflammatory reaction. J Submicrosc Cytol Pathol 31, 571 - 579 (1999)

190 Wang Q, Pelligrino DA, Koenig HM and Albrecht RF: The role of endothelium and nitric oxide in rat pial arteriolar dilatory responses to $\mathrm{CO}_{2}$ in vivo. J Cereb Blood Flow Metab 14, $944-$ 951 (1994)

191 Pelligrino DA, Miletich DJ and Albrecht RF: Diminished muscarinic receptor-mediated cerebral blood flow response in the streptozotocin-treated rat. Am J Physiol 262, E447-E454 (1992)

192 Ikezu T, Ueda H, Trapp BD, Nishiyama K, Sha JF, Volonte D, Galbiati F, Byrd AL, Bassell G, Serizawa H, Lane WS, Lisanti MP and Okamoto T: Affinity-purification and characterization of caveolins from the brain: differential expression of caveolin$1,-2$, and -3 in brain endothelial and astroglial cell types. Brain Res 804, 177 - 192 (1998)

193 Hall ED, Oostveen JA, Andrus PK, Anderson DK and Thomas $\mathrm{CE}$ : Immunocytochemical method for investigating in vivo neuronal oxygen radical-induced lipid peroxidation. J Neurosci Methods 76, 115 - 122 (1997) 